\title{
O EFEITO DA CONCORRÊNCIA DE IMPORTAÇÕES CHINESAS NA SAÚDE DOS TRABALHADORES BRASILEIROS
}

\author{
Alí́cia Cechin * \\ Carlos A. Charris ${ }^{\dagger}$ \\ FERNANDa APARECIDA Silva $¥$ \\ Leonardo Chaves Borges Cardoso $§$
}

\begin{abstract}
Resumo
Este estudo buscou verificar qual o efeito do aumento da concorrência de importações chinesas nos acidentes e doenças do trabalho no Brasil no período de 2000 a 2016. Para isso, utilizou-se o método de variável instrumental, bem como um conjunto de efeitos fixos e variáveis de controle para captar o efeito de interesse. Os resultados obtidos demonstram que o aumento da concorrência de importações chinesas aumentou os acidentes e doenças do trabalho no Brasil no período de 2000 a 2016. Além disso, setores com menor número de empregados apresentam um maior efeito da concorrência de importações chinesas nos acidentes e doenças no trabalho.
\end{abstract}

Palavras-chave: acidentes e doenças do trabalho, concorrência de importação chinesa, choque exógeno, variáveis instrumentais.

Códigos JEL: F1, F16, C01, C36.

\begin{abstract}
This study sought to verify the effect of increased competition from Chinese imports on accidents and illnesses at work in Brazil from 2000 to 2016. For this purpose, the instrumental variable method was used, as well as a set of fixed effects and control variables to capture the effect of interest. The results showed that the increase in competition from Chinese imports positively affected accidents and illnesses at work in Brazil in the period from 2000 to 2016. In addition, sectors with fewer employees have a greater effect of competition from Chinese imports in accidents and diseases at work.
\end{abstract}

Keywords: accidents and occupational diseases, chinese import competition, exogenous shock, instrumental variables.

JEL codes: F1, F16, C01, C36.

DOI: http://dx.doi .org/10.11606/1980-5330/ea172603

\footnotetext{
* Doutora em Economia Aplicada pela Universidade Federal de Viçosa (UFV). E-mail: alicia_cechin@hotmail.com.

† Doutorando no Programa de Pós-Graduação em Economia Aplicada da Universidade Federal de Viçosa (UFV). E-mail: ccharris1988@gmail.com.

$\ddagger$ Doutora em Economia Aplicada pela Universidade Federal de Viçosa (UFV). Professora do Departamento de Economia Rural da UFV. E-mail: fernandasilvaufv@gmail .com.

$\S$ Doutor em Desenvolvimento Econômico pela Universidade Federal do Paraná (UFPR). Professor do Departamento de Economia Rural da UFV. E-mail: leonardocardoso005@gmail.com.
} 


\section{Introdução}

A ligação entre padrões trabalhistas e política comercial internacional, conforme destacam Brown et al. (1996) não é uma questão nova. Porém, assumiu maior importância devido às preocupações de interesses trabalhistas nos Estados Unidos da América (EUA) e em outros países em que essas questões não foram abordadas na Rodada do Uruguai de Negociações Comerciais Multilaterais. Questões sobre padrões laborais também estiveram a cerca do debate na construção do NAFTA (North American Free Trade Agreement). A preocupação girava em torno de que as normas trabalhistas não são cumpridas com maior exigência no México, e com isso, a concorrência que resultaria do NAFTA colocaria as indústrias dos EUA em desvantagem em relação às indústrias mexicanas. A preocupação com o mercado de trabalho, especificamente com normas trabalhistas, é de longa data, especialmente nos países em desenvolvimento. O argumento econômico é de que os países que não garantem e não fazem cumprir os direitos dos trabalhadores em suas empresas podem ter uma vantagem de custo que é indevida, principalmente no que tange ao comércio destinado à exportação (Brown et al. 1996).

No que se refere à concorrência de importações, quando se observa a respectiva literatura, nota-se que essa concorrência impacta a sobrevivência das empresas, como se pode verificar no estudo de Bloom et al. (2016). Impacta também o investimento das firmas em novas tecnologias, como pode ser visto no estudo de Bustos (2011). Ademais, a concorrência das importações influencia o mercado de trabalho, no qual Autor et al. (2013) investigaram o efeito da entrada da China na Organização Mundial do Comércio (OMC) sobre o mercado de trabalho, mais especificamente o emprego dos EUA. Os autores encontraram que a concorrência de importação chinesa explica um quarto do declínio no emprego industrial dos EUA. Além disso, destacaram que transferências de pagamentos de benefícios por desemprego, invalidez, aposentadoria e assistência médica também aumentam em mercados de trabalho mais expostos ao comércio.

Em se tratando do mercado de trabalho, McManus \& Schaur (2016) trazem que dentre os determinantes do bem-estar dos trabalhadores está a saúde ocupacional $^{1}$, que contempla os acidentes e as doenças adquiridas no ambiente laboral. Um aumento na concorrência de importações impacta de maneira positiva os riscos de acidentes/doenças do trabalhador, principalmente pelo aumento da intensidade do trabalho. McManus \& Schaur (2016) destacam que os acidentes de trabalho e as doenças ocorrem devido à prioridade em que a empresa insere a segurança no ambiente de trabalho, além de outros objetivos como a produção. Mudanças na saúde do trabalhador, especialmente para empresas menores, podem reduzir significativamente a produtividade dos trabalhadores e das firmas, bem como as vendas.

Neste estudo, buscou-se dar um passo para preencher a lacuna entre as duas literaturas, concorrência de importação e saúde dos trabalhadores, examinando como um choque comercial, em particular, o aumento das importações chinesas, afetou a saúde do trabalhador no Brasil. Para abordar essa relação, considerou-se um choque de oferta decorrente de mudanças exógenas no mercado de importação. No Brasil, verifica-se um significativo aumento

\footnotetext{
${ }^{1}$ Setor específico dentro da grande área da saúde, porém, que lida unicamente com a saúde voltada para o trabalhador.
} 
nos acidentes e doenças do trabalho no período de 2000 a 2016. Em 2000, o número de acidentes e doenças do trabalho era de 363.868 em todo o país considerando todos os setores. E em 2016, observa-se um número de acidentes e doenças do trabalho de 585.626. Do primeiro ano da análise (2000) para o último (2016), pode-se notar um crescimento de aproximadamente $60,94 \%$ nos acidentes e doenças do trabalho, conforme dados da Empresa de Tecnologia e Informações da Previdência Social (DATAPREV 2019).

A inserção da economia chinesa como uma força importante na economia global é um dos maiores eventos econômicos dos últimos anos (Costa et al. 2016). No caso brasileiro, tem-se um cenário adequado para um estudo do efeito da China. Primeiramente, a China nos últimos anos tem sido o principal mercado, tanto para as exportações como para as importações brasileiras. A motivação para utilização do choque comercial, medido por meio do aumento das importações de produtos advindos da China pelo Brasil, está na consideração de que o seu aumento afetou a balança comercial do Brasil. Houve um rápido aumento nas importações chinesas, a partir de 2001, ano em que a China entrou para a OMC. De 2000 para 2019, as importações brasileiras advindas da China apresentaram uma taxa média anual de crescimento de 22,80\%, conforme dados do MDIC - Ministério da Indústria, Comércio Exterior e Serviços (2019).

Além disso, como trazem Costa et al. (2016), o padrão de comércio entre esses dois países contempla uma pauta de exportação baseada em produtos de menor intensidade tecnológica, sendo eles, produtos do setor agrícola e extração ${ }^{2}$. E uma pauta de importação composta por produtos com maior conteúdo tecnológico, ou seja, produtos manufaturados ${ }^{3}$ (em que essa mesma tendência segue para outros países em desenvolvimento). Ademais, o Brasil possui um território extenso e diversificado, gerando assim, um conjunto de mercados locais variados em relação às suas vantagens comparativas, ou seja, a exposição a esse choque comercial varia entre regiões especializadas em diferentes setores. Nesse cenário, os setores de manufatura que competem de modo mais direto com as importações chinesas tendem a sofrer um maior efeito. Sendo assim, a diversificação regional e setorial brasileira permite uma melhor identificação dos efeitos heterogêneos do aumento das importações chinesas no país (Costa et al. 2016).

Este estudo contribui para uma literatura crescente que aborda os efeitos mundiais da ascensão chinesa, como é o caso de Autor et al. (2013) e Pierce \& Schott (2016), que abordaram o impacto da concorrência de importações da China em variáveis econômicas, como o emprego na indústria dos EUA. O artigo que mais se aproxima da análise pretendida é o de McManus \& Schaur (2016), no qual os autores aferem se a concorrência de importações do mercado externo afetou as lesões e as doenças dos trabalhadores nas empresas de manufatura americanas, considerando o crescimento das importações chinesas de 1996 a 2007, em nível de firma, como um choque para a concorrência, neste ensaio, segue-se a abordagem de Autor et al. (2013) que relaciona mudança nos resultados do mercado de trabalho dada a exposição à concorrência de importações chinesas e emprega-se a questão de como os choques

\footnotetext{
${ }^{2}$ Podendo destacar a soja, minério de ferro e petróleo (MDIC - Ministério da Indústria, Comércio Exterior e Serviços 2019)

${ }^{3}$ Em que destaca-se plataformas de perfuração ou de exploração; medicamentos; óleos combustíveis; partes e peças para veículos automotores e tratores; óleos brutos de petróleo; eletrônicos, entre outros (MDIC - Ministério da Indústria, Comércio Exterior e Serviços 2019).
} 
comerciais, ou seja, o aumento da concorrência de importações, pode afetar os acidentes e doenças do trabalho no Brasil.

Buscou-se responder a seguinte questão: $\mathrm{O}$ aumento da concorrência de importações da China teve efeito nos acidentes e doenças do trabalho no Brasil, no período de 2000 a 2016? Nesse sentido, analisou-se a relação entre os acidentes e doenças do trabalho ocorridos no Brasil e o aumento da concorrência de importação da China, no período de 2000 a 2016, considerando a composição setorial de cada estado. Ademais, verificou-se se o aumento da concorrência de importações chinesas afetou de maneira diferente os acidentes e doenças do trabalho em setores com maior e menor número de empregados. Além disso, avaliou-se o efeito do aumento das importações chinesas no Brasil, no período de 2000 a 2016, sobre os acidentes e doenças do trabalho, nos diferentes setores (comercializável e não comercializável).

Diferentemente de McManus \& Schaur (2016), o presente estudo analisou se a concorrência de importações de produtos chineses afetou os acidentes e doenças dos trabalhadores brasileiros, para cada Classificação de Atividade Econômica (CNAE), em nível de quatro dígitos ${ }^{4}$. Considerando a diversificação regional brasileira, cada estado pode sentir de modo diferente o aumento das importações chinesas, devido a sua composição setorial. Sendo assim, a análise foi feita em nível de estado, para avaliar diferentes comportamentos. A amostra foi dividida em setores com maior e menor número de empregados, para verificar se os setores com menor número de empregados apresentam um maior efeito da concorrência de importações sobre os acidentes e doenças do trabalho, conforme a literatura sugere. O período de análise de 2000 a 2016 justifica-se pelo fato de o ano de 2000 ser anterior à entrada da China na OMC (que ocorreu em 2001) e também pelo expressivo crescimento do comércio Brasil-China nesse período considerado.

Os resultados obtidos corroboram a literatura existente ${ }^{5}$, demonstrando que o aumento da concorrência de importações chinesas aumentou os acidentes e doenças do trabalho no Brasil no período de 2000 a 2016. Além disso, verificou-se que a magnitude do efeito é maior no curto e médio prazo. Ademais, foram considerados diferentes quartis de trabalhadores, com a intenção de verificar se o efeito é maior em setores com menor número de empregados e, observa-se que o efeito é maior onde se encontram os setores que possuem o menor número de trabalhadores. Foram considerados nessa análise também os setores comercializáveis (que competem diretamente com os produtos chineses) e os setores não comercializáveis. Quando se considera os setores comercializáveis, o efeito encontrado é positivo e significativo. No entanto, em relação aos setores não comercializáveis, observa-se que os mesmos não possuem significância estatística, o que já era de se esperar, dado que esses setores não competem diretamente com produtos advindos da China.

O presente estudo está estruturado em mais quatro seções, além da introdução. A segunda seção apresenta o referencial teórico que oferece a base para as análises. A terceira parte explica a metodologia utilizada, enquanto a quarta seção expõe os resultados obtidos e as discussões do estudo. E, por fim, a quinta seção mostra as principais conclusões.

\footnotetext{
${ }^{4}$ No Apêndice Apêndice A elencam-se os setores considerados na análise.

${ }^{5}$ Ver McManus \& Schaur (2016)
} 


\section{Referencial Teórico}

Hummels et al. (2015) consideraram em seu modelo que horas a mais trabalhadas devido a maiores chances de exportação induzem um aumento no número de lesões (acidentes de trabalho). Os autores encontraram evidências empíricas em nível de empresa na Dinamarca para esse efeito. Diferentemente dos autores mencionados, McManus \& Schaur (2016) demonstraram por que empresas que enfrentam o aumento da concorrência de importações (aumento da oferta de produtos) reduzem a segurança dos trabalhadores, para obter maior produtividade e com isso aceitar um aumento nos riscos de acidentes e doenças do trabalho. Este estudo segue o modelo teórico de McManus \& Schaur (2016). Embora os autores desenvolvam o modelo para empresas que enfrentam a concorrência de importações, o modelo pode ser utilizado na análise por setores, já que os mesmos são compostos por empresas.

A empresa necessita do esforço do trabalhador para a produção. A empresa emprega $T$ trabalhadores homogêneos e obtém de cada um uma quantia de esforço, denotado por e. Assume-se que a empresa tem retornos constantes no esforço total, que apresenta uma função de produção $q=F(e, T)=\theta e T$, em que $\theta$ é um parâmetro de produtividade exógena da empresa. Para os trabalhadores, há um custo para os trabalhadores exercerem os esforços. Sendo assim, a empresa deve direcionar recursos para monitorar sua produção. $\mathrm{O}$ esforço do trabalhador em função do salário recebido e da quantidade de monitoramento $m$ é obtido por meio de: $e(m)=w^{\alpha} m^{\beta}$, em que $\alpha>0$ e $\beta<1$, em que o esforço é crescente e côncavo no salário e no nível de monitoramento.

Os trabalhadores enfrentam o risco de acidentes e/ou doenças ocupacionais a cada período em consequência de seu trabalho. E esses acidentes/doenças têm um custo significativo para as empresas. Na prática, algumas empresas pagam custos diretos por essas lesões como, por exemplo, pagamento de indenização. E as empresas também incorrem em custos indiretos resultante de acidentes do trabalho, como interrupções na produção, danos ao capital, custos em treinamento e contratação de novos empregados, redução da produtividade dentre outros. Simplificando, a partir de agora, utiliza-se o termo acidentes do trabalho para descrever qualquer evento que possui relação com o trabalho e que afeta de maneira negativa a saúde do trabalhador.

Os autores modelam os custos de acidentes do trabalho de forma reduzida, supondo que a empresa vai incorrer em alguns custos futuros dado os acidentes do trabalho hoje. Assume-se que em cada período existe a probabilidade exógena $\lambda$ de que uma empresa saia do mercado, como em Melitz (2003). O custo total esperado de um acidente do trabalho hoje é dado por:

$$
E[C]=\int_{t=0}^{\infty}(1-\lambda)^{t} e^{-r t} c(t) d t
$$

em que $c(t)$ é o custo incorrido $t$ períodos após um acidente do trabalho; a taxa de juros $r$ é utilizada como taxa de desconto da empresa. Assume-se que os custos de acidente do trabalho são depreciados ao longo do tempo a uma taxa $d$ tal que $c(t)=c d^{t}$. O custo total sobre a vida útil da empresa que incorreu em um acidente do trabalho hoje é dado por ${ }^{6}$ :

\footnotetext{
${ }^{6}$ Onde é derivado da seguinte maneira: Seja $C_{t}$ o custo de um acidente do trabalho no tempo para todos os períodos futuros. Por períodos de duração $\Omega, C_{t}=\Omega c+(1-r \Omega)(1-\lambda \Omega) C_{t+1}$. Para
} 


$$
E[C]=\frac{c}{(\lambda+r) d}
$$

A mão de obra fornecida à empresa pode elevar-se por meio do aumento no número de trabalhadores ou um aumento na intensidade do trabalho, conforme elencam Hummels et al. (2015). Exemplos desse último canal incluem trabalhar horas adicionais e/ou trabalhar em um ritmo mais acelerado, por exemplo. Destaca-se que, inúmeras vezes, a empresa opta por aumentar a intensidade do trabalhador que já está há mais tempo na empresa, do que a contratação de um novo, pois tem um custo à contratação e, além disso, existe a incerteza sobre a produtividade/habilidade desse novo funcionário. Pesquisas médicas mostraram que trabalhar longas jornadas está associado a uma ampla gama de resultados negativos para a saúde, incluindo pressão arterial mais alta, nível mais alto de cortisol, depressão, maior probabilidade de doença arterial coronariana, derrames e até morte. Além disso, agachamento prolongado e trabalho com as mãos estão associados à dor corporal generalizada $^{7}$.

Um ponto importante a ser mencionado é que os custos de acidentes do trabalho só ocorrem em períodos futuros se a empresa ainda estiver operando no mercado. Sendo assim, os custos esperados para as empresas que incorrem em acidentes do trabalho reduzem na medida em que essa empresa tem a probabilidade de sair do mercado, fazendo com que a empresa opere com taxas mais elevadas de acidentes do trabalho.

Além de monitorar o esforço, a empresa decide alocar uma quantia $s$ de seus recursos $X$, como, por exemplo, o tempo do gerente para aprimorar a segurança no local de trabalho e, com isso, diminuir a probabilidade de acidentes do trabalho. Assume-se que a probabilidade de um trabalhador sofrer um acidente do trabalho é dada por: $P(s)=\left(1-\frac{s}{X}\right)^{\gamma}$ para $s \in[0, X]$, em que $\gamma \geq 1$, de modo que o retorno à segurança (menores taxas de acidente de trabalho) não é crescente. Simplificando, assume-se que a empresa possui restrição nos seus recursos, em que $m+s=X$, ou seja, os recursos atribuídos ao monitoramento são os recursos não gastos para aprimorar a segurança (exemplo, o tempo do gerente).

A distribuição probabilística de acidente do trabalho em função do monitoramento do esforço é: $P(m)=\left(\frac{m}{X}\right)^{\gamma}$ para $m \in[0, X]$, em que $P_{m}>0$ e $P_{m m}>0$. A relação positiva entre a quantidade de acidentes do trabalho e a produtividade (por meio do esforço extraído) nesse modelo surge de maneira endógena, com base na suposição de que a empresa possui restrição nos seus recursos e decide de que modo vai impulsionar a produção e de que modo vai impulsionar o esforço dado um aumento da concorrência de importações. Normaliza-se $X=1$, dessa maneira, $m$ pode ser entendido como a parcela de recursos que a empresa direciona para a melhoria da segurança. Assume-se que a probabilidade de um trabalhador sofrer um acidente de trabalho não dependa do número de trabalhadores na empresa. Sendo assim, o custo total esperado de um acidente de trabalho em um período é:

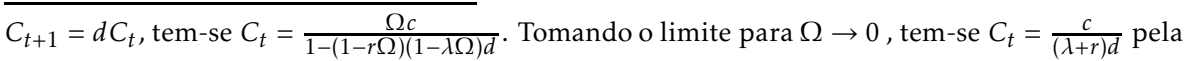
regra de L'Hopital.

${ }^{7}$ Ver Kivimäki \& Kawachi (2015), O’Reilly \& Rosato (2013), Virtanen et al. (2012) e Harkness et al. (2004).
} 


$$
C T=m^{\gamma} \frac{c}{(\lambda+r) d} T
$$

A probabilidade de sobrevivência da empresa é considerada exógena, e, com isso, as escolhas feitas hoje irão afetar no futuro apenas na medida em que os acidentes de trabalho hoje possuem custos significativos em períodos futuros. A função de custo de acidentes do trabalho captura essa dinâmica, sendo assim, a empresa enfrenta um problema estático:

$$
\begin{gathered}
\max _{m, T} \pi=\theta^{\rho}\left(w^{\alpha} m^{\beta} T\right)^{\rho}-w T-m^{\gamma} \frac{c}{(\lambda+r) d} T \\
\text { s. } a \leq m \leq 1
\end{gathered}
$$

Quando os autores trazem essa relação, a de que para manter-se no mercado muitas vezes as empresas necessitam exigir maior produtividade do trabalhador para tornarem-se mais competitivas (dada a entrada de produtos estrangeiros no país com menor preço, principalmente da China que tem importantes efeitos salariais e de emprego) e, com isso, incorrer em maiores riscos de acidentes e/ou doenças de trabalho, é no sentido em que as particularidades do modelo teórico são que a empresa se defronta com um trade-off entre melhorar a produtividade (dado um choque comercial de aumento de importações) e proteger os trabalhadores contra acidentes do trabalho.

McManus \& Schaur (2016) destacam que os acidentes de trabalho bem como as doenças ocorrem em decorrência da prioridade em que a empresa insere a segurança no ambiente de trabalho, além de outros objetivos como a produção, investimento, aquisição de novas máquinas/equipamentos, atualização tecnológica, dentre outros fatores. E os incentivos relativos de cada um dependem da força da empresa no mercado e, além disso, da sua limitação em relação aos seus recursos disponíveis. Como a análise é concentrada na saúde/acidentes do trabalhador, simplifica-se o problema tratando os salários como fixos e normalizando-os para um. O nível ótimo de monitoramento de esforço para empresa é dado pela solução interior:

$$
m^{*}=\left[\left(\frac{\beta}{\gamma-\beta}\right)\left(\frac{d(\lambda+r)}{c}\right)\right]^{\frac{1}{\gamma}}
$$

se $\frac{c}{d(\lambda+r)} \geq \frac{\beta}{\gamma-\beta}$, que a partir de agora assume-se como verdade. A quantidade de esforço de equilíbrio executada pelos empregados na empresa e a probabilidade de sofrerem um acidente de trabalho são:

$$
\begin{aligned}
& e\left(m^{*}\right)=\left[\left(\frac{\beta}{\gamma-\beta}\right)\left(\frac{d(\lambda+r)}{c}\right)\right]^{\frac{\beta}{\gamma}} \\
& P\left(m^{*}\right)=\left[\left(\frac{\beta}{\gamma-\beta}\right)\left(\frac{d(\lambda+r)}{c}\right)\right]
\end{aligned}
$$


A quantidade de trabalho ótima empregada pela empresa é dada por:

$$
T^{*}=\left[\rho \theta^{\rho}\left(\frac{\beta}{\gamma-\beta}\right)^{\frac{\beta \rho}{\gamma}}\left(\frac{\gamma-\beta}{\gamma}\right)\left(\frac{d(\lambda+r)}{c}\right)^{\frac{\beta \rho}{\gamma}}\right]^{\frac{1}{1-\rho}}
$$

O aumento resultante do esforço exigido pela empresa torna cada unidade de trabalho mais produtiva. McManus \& Schaur (2016) trazem que um aumento na probabilidade de a empresa encerrar suas atividades, $\lambda$, leva as empresas a reduzirem a segurança no local de trabalho em troca de um maior esforço dos trabalhadores e a aceitarem um aumento na taxa de acidentes e doenças do trabalho. As empresas que enfrentam a concorrência das importações e lutam pela sobrevivência no mercado aumentam a produtividade e prolongam sua existência, provavelmente sacrificando a saúde e a segurança de seus funcionários durante esse processo.

\section{Metodologia}

\subsection{Estratégia Empírica}

Pode-se interpretar um choque, como qualquer alteração não antecipada que pode afetar o bem-estar de um indivíduo ${ }^{8}$. Neste estudo, o interesse incide sobre um choque econômico. A especificação econométrica deste estudo utilizou três estratégias: seleção em observáveis, controle das variáveis não observadas utilizando o método de variável instrumental bem como um conjunto de efeitos fixos, para captar o efeito de interesse da problemática estabelecida.

Com o intuito de isolar o efeito das variáveis que são observadas, recorre-se a CIA (Suposição de Independência Condicional), podendo também ser chamada de seleção em observáveis, que conforme Angrist \& Pischke (2008), a mesma garante que condicional as características observáveis, desaparecerá o viés de seleção. Pela CIA, assume-se que as diferenças de resultados potenciais do número de acidentes e doenças do trabalho entre os estados mais e menos afetados pelas importações oriundas da China devem-se a fatores observáveis, mas sabe-se que existem fatores não observáveis também que afetariam esses resultados potenciais, como é o caso da habilidade/capacidade do trabalhador.

Nesse sentido, utilizou-se um vetor de controles em que contém as variáveis mensuradas por estado e setor: idade, sexo, raça, ocupação, escolaridade, estado civil e tamanho do estabelecimento, com o intuito de isolar os diferentes efeitos sentido nos estados devido ao aumento da concorrência de importação de produtos chineses. De acordo com Angrist \& Pischke (2008), o controle de variáveis pode elevar a probabilidade de que as estimativas da regressão possuam interpretação causal (através da CIA). Sendo assim, com as variáveis observadas estabelecidas no modelo e fazendo-se valer da CIA, e com o controle das variáveis não observadas utilizando o método de variável instrumental e efeitos fixos, garante-se que a regressão fornece o efeito causal de interesse.

\footnotetext{
${ }^{8}$ Para mais informações ver Dix-Carneiro et al. (2018), Gaddis \& Pieters (2017) e Benguria \& Ederington (2017)
} 
O problema em estimar a causalidade entre choques de importação e acidentes e doenças do trabalho está no fato de que ambos podem ser explicados por fatores não observáveis, como é o caso da habilidade, capacidade dos trabalhadores, sofisticação/estrutura das empresas dentre outros. Na impossibilidade de se conduzir experimentos aleatórios que gerem choques de aumento de importação entre os setores brasileiros (ou seja, se as importações fossem feitas de maneira aleatória entre os estados brasileiros) e com o intuito de aproximar-se do efeito causal esperado, o trabalho utilizou como proxy a variação das importações brasileiras advindas da China, como proposto por Autor et al. (2013) e McManus \& Schaur (2016).

Os autores destacam que mensurar a concorrência de importações utilizando o crescimento das importações advindas da China por setor fornece excelentes variações de identificação entre setores e tempo. No entanto, essa medida possui correlação com choques de demanda. Se estimar a equação (10) por MQO (Mínimos Quadrados Ordinários), os coeficientes obtidos serão viesados, caso os choques de demanda também afetem os acidentes e doenças do trabalho ${ }^{9}$. Para controlar esse possível viés, empregou-se a estratégia de variáveis instrumentais para identificar de modo exógeno o crescimento das importações estimulado por choques de oferta.

A estratégia empírica empregada neste ensaio segue Autor et al. (2013), McManus \& Schaur (2016) e Benguria \& Ederington (2017), em que estimouse a seguinte equação:

$$
\begin{aligned}
\ln \left(A D T_{j, r, t}\right)=\beta_{0} & +\beta_{1}^{t} \ln \Delta \text { Concorrência_Chinesa } a_{j, r, t}+\beta_{2}^{t}\left(X_{j, r, t}^{\prime}\right) \\
& +\tau_{j}+\theta_{t}+\phi_{r}+\mu_{r, t}+\varepsilon_{j, r, t}
\end{aligned}
$$

denomina-se $j$ como setores, $r$ como estado e $t$ como anos.

$A D T_{j, r, t}{ }^{10}$, são os Acidentes e Doenças do Trabalho ${ }^{11}$, que de acordo com o Anuário Estatístico de Acidentes do Trabalho (2019), os benefícios de natureza acidentária concedidos pelo Instituto Nacional do Seguro Social (INSS), seja de Auxílio-Doença ou de Aposentadoria por Invalidez, são concedidos aos contribuintes do Regime Geral de Previdência Social (RGPS), que pertencem às categorias: empregado, empregado doméstico, trabalhador avulso e segurado especial.

Sendo assim, para o cálculo do número de acidentes/doenças do trabalho, levaram-se em consideração os empregados com carteira assinada e os trabalhadores avulsos (autônomo, conta-própria) que são contribuintes do RGPS. Dado que a Relação Anual de Informações Sociais (RAIS) leva em consideração apenas os empregados com carteira assinada, utilizou-se o Censo Demográfico de 2000 e 2010 fornecido pelo Instituto Brasileiro de Geografia e Estatística (IBGE) para obter a participação dos empregados com carteira assinada e os trabalhadores avulsos contribuintes do RGPS no total de trabalhadores em cada setor por ano e estado. Depois de obtida essa participação,

\footnotetext{
${ }^{9}$ Hummels et al. (2015) demonstram que um choque de demanda aumenta o total de lesões, tornando a produção mais cara.

${ }^{10}$ Seguindo autores como Almeida \& Araújo Júnior (2017), McManus \& Schaur (2016) e Esteves (2008).

${ }^{11} \mathrm{O}$ total de acidentes do trabalho é composto por: acidentes com Comunicação de Acidente do Trabalho (CAT) registrada - acidentes típicos, decorrentes das peculiaridades da atividade profissional e acidentes de trajeto-; doença do trabalho, produzidas ou desencadeadas pelo exercício do trabalho relativo a determinado ramo de atividade e acidentes sem CAT registrada.
} 
multiplicou-se o valor adquirido pelo número de acidentes/doenças por setor e estado, para conseguir a parcela do número de acidentes/doenças do trabalho que representa os trabalhadores com carteira assinada e os trabalhadores avulsos, contribuintes do RGPS.

$$
\Delta \text { Concorrência_Chinesa }{ }_{j, r, t}=\sum_{j} \frac{E m p_{j, r, 2000}}{E m p_{r, 2000}} \cdot \frac{\Delta I m p_{j}}{E m p_{j, 2000}}
$$

em que $\Delta I m p_{j}$ é a variação na importação de produtos chineses em cada setor entre o ano anterior à entrada da China na OMC (2000) e os anos posteriores (até 2016). Sendo assim, o índice é uma média das importações brasileiras de produtos advindos da China entre 2000-2016, ponderada pela parcela de emprego no setor $j$ para cada estado $r$ no ano base, $\frac{E m p_{j, r, 2000}}{E m p_{r, 2000}}$, normalizada pelo emprego nacional no setor $j$, no ano base, $E m p_{j, 2000}$. Assim, estamos medindo a variação na exposição de um estado ao choque comercial chinês através da variação na estrutura dos setores nos estados brasileiros (isto é, os estados que são mais especializados em setores intensivos em importações oriundas da China são considerados mais expostos).

Além disso, considerou-se um vetor de controles, $X_{j, r, t}^{\prime}$, que contém as seguintes variáveis: idade, sexo, raça, ocupação, escolaridade, estado civil e tamanho do estabelecimento. Com o intuito de verificar se o efeito do aumento da concorrência de importações sobre o número de acidentes e doenças do trabalho é maior em setores com menor número de empregados (que tem menor tamanho de estabelecimento), a equação (10) também foi estimada considerando diferentes faixas de trabalhador por setor.

$\tau_{j}$ é o efeito fixo para os setores, $\theta_{t}$ é o efeito fixo específico de ano, $\phi_{r}$ é o efeito fixo de estado, $\mu_{r, t}$ é a tendência linear específica de estado e $\varepsilon_{j, r, t}$ é o termo de erro. Os efeitos fixos mitigam o efeito de características específicas de setor, produtos, estados etc., que não são observadas. Sendo assim, os efeitos fixos foram incluídos com o intuito de garantir que nenhuma informação seja transferida para o termo de erro, e/ou esteja correlacionada com a variável instrumental ou que resultem em preocupações de endogeneidade na variável que considera-se exógena no modelo.

Espera-se encontrar um efeito positivo entre as variáveis de interesse, considerando que o aumento na concorrência das importações de produtos chineses aumentou o número de acidentes e doenças do trabalho, principalmente em setores com menor número de empregados. Isso pode ser explicado pelo fato de que empresas menores são mais atingidas pela concorrência de importação, por meio da deterioração da segurança no local de trabalho. No entanto, para as empresas maiores, espera-se um menor efeito, pois essas empresas investem em novas tecnologias e o aumento dos lucros no mercado externo pode refletir em melhorias nas condições de trabalho.

A utilização do instrumento tem como objetivo trabalhar com a possibilidade de existência de correlação entre a intensidade da entrada de produtos chineses no Brasil e qualquer outro fator que seja interno a economia brasileira que também pode afetar a $A D T$. Essa estratégia de variável instrumental ajuda na identificação, desde que o aumento das importações chinesas seja devido ao crescimento da China ou à queda dos custos comerciais e não devido a mudanças na produtividade específica de um setor ou alterações nos padrões 
de consumo associados a modificações da renda no Brasil, por exemplo. Sendo assim, a ideia central da utilização da variável instrumental é encontrar um meio de separar a variação exógena do regressor endógeno.

Seguindo Autor et al. (2013), McManus \& Schaur (2016), instrumenta-se o crescimento das importações brasileiras advindas da China com o crescimento das importações de outro conjunto de países. Os autores anteriormente mencionados utilizaram países de alta renda e os países da OCDE, respectivamente. Nesse estudo, segue-se Benguria \& Ederington (2017) e utilizam-se os países da América Latina com características e economias parecidas ao Brasil (como Argentina, Bolívia, Chile, Colômbia, Equador, Paraguai, Peru, Uruguai e Venezuela):

$$
\Delta \text { Concorrência_Chinesa } a_{j, r, t}^{A m e \_L a t}=\sum_{j} \frac{E m p_{j, r, 2000}}{E m p_{r, 2000}} \cdot \frac{\Delta I m p_{j}^{A m e_{-} L a t}}{E m p_{j, 2000}}
$$

em que $\Delta I m p_{j}^{A m e \_L a t}$ é a variação das importações dos países da América Latina advindas da China em cada setor. Sendo assim, utilizando Mínimos Quadrados em Dois Estágios (MQ2E), no primeiro estágio regride-se a variável endógena (equação (11)) no instrumento (equação (12)) e posteriormente a equação de interesse foi estimada da seguinte maneira:

$$
\begin{aligned}
\ln \left(A D T_{j, r, t}\right)=\beta_{0} & +\beta_{1}^{t} \ln \Delta \text { Concorrência_Chinesa } a_{j, r, t}+\beta_{2}^{t}\left(X_{j, r, t}^{\prime}\right) \\
& +\tau_{j}+\theta_{t}+\phi_{r}+\mu_{r, t}+\varepsilon_{j, r, t}
\end{aligned}
$$

O principal pressuposto de identificação para as variáveis instrumentais é que o crescimento correlacionado entre os mercados é estimulado por mudanças nos custos de comércio e na produtividade da China. Assim, as estimativas através do MQ2E na equação (13) são consistentemente identificadas. Ademais, os erros-padrão foram clusterizados em nível de macrorregião, com o intuito de considerar correlações potenciais entre os estados próximos. Além disso, foram ponderados os dados pela população de cada estado para o ano 2000. Isso foi feito, pois se a regressão (13) não fosse ponderada pela população dos estados, a heterogeneidade existente entre os estados poderia não ser totalmente controlada pelos efeitos fixos de estado. Para obter-se o efeito causal de interesse, supõe-se que as características não observadas em nível de estado, mantiveram-se constantes no tempo, ou seja, na ausência do crescimento das importações oriundas da China, o aumento nos acidentes e doenças do trabalho não teria sido diferente nos estados.

Seguindo McManus \& Schaur (2016) estimou-se a equação (13) fazendo-se a diferenciação em relação ao tempo, em que os autores consideram que as diferenciações distinguem entre os efeitos a curto e longo prazo da concorrência de importações chinesas e os acidentes/doenças do trabalho. Ou seja, a diferenciação ajuda a explicar a heterogeneidade não observada nas características dos setores que podem afetar os acidentes/doenças do trabalho, tais como custos de acidentes/doenças, diferenças regulatórias, avanço tecnológico das empresas/setores, aquisição de maquinário, dentre outros. Sendo assim, levando em consideração o período de análise, 2000 a 2016, foram feitas as estimativas considerando as seguintes diferenciações: 2000 a 2015 (diferenciação 
de 1 ano); 2000 a 2014 (diferenciação de 2 anos); 2000 a 2013 (diferenciação de 3 anos) e assim sucessivamente, até 2000 a 2004 (diferenciação de 12 anos), para analisar a existência de efeitos de curto e longo prazo.

\subsection{Mecanismo}

Em se tratando do mecanismo pelo qual o aumento da concorrência de importações chinesas tende a impactar os setores no Brasil, segue-se a abordagem de Autor et al. (2013). Relaciona-se à mudança no mercado de trabalho dada a exposição à concorrência de importações chinesas e emprega-se à questão de como os choques comerciais, ou seja, o aumento da concorrência de importações pode afetar o número de acidentes e doenças do trabalho. O mecanismo testado foi a renda dos trabalhadores brasileiros.

Ao examinar os resultados econômicos em nível de estado, consegue-se captar o efeito direto dos choques comerciais sobre a renda dos empregados nos setores concorrentes das importações chinesas. Desse modo, utilizou-se a variável renda, que foi obtida através do Censo Demográfico, no qual se considera a renda em valor real (deflacionada para o ano de 2016) e a renda em salários mínimos, para cada ano considerado na análise (2000 a 2016), setor e estado, rend $a_{j, r, t}$, em que estimou-se:

$$
\begin{aligned}
\ln \left(\text { rend }_{j, r, t}\right)=\beta_{0} & +\beta_{1}^{t} \ln \Delta \text { Concorrência_Chinesa } \\
j, r, t & +\beta_{2}^{t}\left(X_{j, r, t}^{\prime}\right) \\
& +\tau_{j}+\theta_{t}+\phi_{r}+\mu_{r, t}+\varepsilon_{j, r, t}
\end{aligned}
$$

em que Concorrência_Chinesa $a_{j, r, t}$ é a medida de exposição por estado ao aumento da concorrência das importações chinesas; $X_{j, r, t}^{\prime}$ são as variáveis de controle; $\tau_{j}$ é o efeito fixo para os setores; $\theta_{t}$ é o efeito fixo específico de ano; $\phi_{r}$ é o efeito fixo de estado, $\mu_{r, t}$ é a tendência linear específica de estado e $\varepsilon_{j, r, t}$ é o termo de erro.

\subsection{Robustez}

Empresas menores são mais afetadas pela concorrência de importações não apenas pelo fato de serem menos produtivas, mas também porque produzem bens de menor qualidade. No entanto, empresas que são mais produtivas, podem escapar do afinco do mercado através da melhoria da qualidade de seus produtos e da tecnologia (Antoniades 2015, Bustos 2011, Kugler \& Verhoogen 2012). De acordo com McManus \& Schaur (2016), as empresas respondem à concorrência das importações melhorando a qualidade dos produtos e investindo em novas tecnologias.

A literatura que trata sobre o comércio internacional de modo específico a qualidade das exportações, discute amplamente o tema com o intuito de encontrar uma proxy adequada para a estimar a qualidade das exportações (Alcalá 2016, Anwar \& Sun 2018, Brambilla \& Porto 2016, Flach 2016, Hallak 2006, Hallak \& Schott 2011, Hummels \& Klenow 2005). Segundo Pinheiro et al. (2002), a qualidade de um produto representa um conceito multidimensional que possui características mensuráveis e imensuráveis. Para os autores, nas características mensuráveis incluem-se o desempenho, conformidade e durabilidade do produto, enquanto nas imensuráveis incluem-se tradição, reputação e fatores culturais de cada país, por exemplo, motivos nos quais dificultam a mensuração da qualidade de um produto. 
Neste estudo, conforme Alcalá (2016), Brambilla \& Porto (2016) e Bas \& Strauss-Kahn (2015), utiliza-se como proxy para mensurar a qualidade das exportações brasileiras, o preço unitário. O mesmo é obtido dividindo o valor total das exportações do produto $j$ do país exportador $r$ (nesse caso os estados do Brasil) no tempo $t$ pela quantidade exportada em $\mathrm{kg}$ do produto $j$ do estado exportador $r$ no tempo $t$. Essa forma de mensuração sugere que preços unitários mais altos resultam em produtos de maior qualidade.

$$
\text { qualidade }_{j, r, t}=\frac{\text { Valor Total de Exportação }_{j, r, t}}{\text { Quantidade Exportada }(k g)_{j, r, t}}
$$

Foram considerados todos os produtos exportados pelos estados no período de 2000 a 2016, por NCM ao nível de 8 dígitos. Como a análise do presente estudo concentra-se em setores, utilizando-se as tabelas de correspondências foram transformados os códigos para padronizar os dados, como pode ser visualizado na Tabela 1, em que estimou-se:

$$
\begin{aligned}
\ln \left(A D T_{j, r, t}\right)=\beta_{0} & +\beta_{1}^{t} \ln \Delta \text { Côncorrência_Chinesa } \\
j, r, t & +\beta_{2}^{t}\left(X_{j, r, t}^{\prime}\right) \\
& +\beta_{3}^{t}\left(\text { qualidade }_{j, r, t}\right)+\tau_{j}+\theta_{t}+\phi_{r}+\mu_{r, t} \\
& +\varepsilon_{j, r, t}
\end{aligned}
$$

\subsection{Fonte de Dados}

No que se refere à base de dados, para construir a variável dependente, acidentes e doenças do trabalho, utilizou-se o Anuário Estatístico de Acidentes de Trabalho (AEAT), da Previdência Social (DATAPREV), que contém os dados de acidentes e doenças do trabalho de 2000 a 2016, por Classificação Nacional de Atividade Econômica (CNAE) ao nível de quatro dígitos, por ano e estado. Em relação às importações advindas da China, foi utilizada a base de dados do WITS - World Integrated Trade Solution (2019) para extrair as importações, tanto para o Brasil como para os outros países da América Latina, para o período de 2000 a 2016, conforme classificação do Sistema Harmonizado (SH), ao nível de 6 dígitos. Como as importações estão classificadas de acordo com o SH, utilizou-se a tabela de correspondência disponibilizada pelo IBGE para transformar em CNAE, conforme os dados de acidentes/doenças do trabalho.

Foi utilizada a base de dados do Censo Demográfico 2000 e 2010 para obter os dados do número de empregados por setor, conforme a classificação CNAE para os anos da análise, em nível de estado. Para as demais variáveis de controle mencionadas anteriormente (idade, sexo, raça, escolaridade, estado civil), também foi utilizado o Censo Demográfico. O tamanho do estabelecimento foi obtido na base de dados da RAIS, para os respectivos anos da análise. A variável ocupação foi construída conforme Costa et al. (2016), na qual os autores classificam os setores como "qualificados" e "não qualificados" de acordo com os códigos CNAE, recebendo o valor 1 para os setores "qualificados" e o valor 0 para os setores "não qualificados".

A qualidade das exportações foi construída por meio dos dados sobre exportação disponibilizados pelo MDIC, ao nível de 8 dígitos do NCM, em que o mesmo foi transformado em CNAE para compatibilização com o restante da base de dados. Como os códigos de cada base de dados deste estudo estão 
classificados de uma maneira, foi necessária a utilização das tabelas de correspondência disponibilizada pelo IBGE para deixar todas as informações na mesma classificação. Segue a Tabela 1 abaixo com as transformações.

Tabela 1: Correspondência base de dados

\begin{tabular}{|c|c|c|c|}
\hline $\begin{array}{c}\text { Base de } \\
\text { Dados/Variável }\end{array}$ & $\begin{array}{l}\text { Classificação } \\
\text { Original }\end{array}$ & Correspondência & $\begin{array}{l}\text { Classificação } \\
\text { Final }\end{array}$ \\
\hline $\begin{array}{l}\text { Importações } \\
\text { Chinesas }\end{array}$ & $\begin{array}{c}\text { Sistema } \\
\text { Harmonizado } \\
6 \text { dígitos }\end{array}$ & $\begin{array}{c}\text { SH_6 dig X CNAE_4 dig } 2.0 \\
\text { CNAE 2.0 X CNAE DOM 2.0 } \\
\text { CNAE DOM 2.0 X CNAE DOM } 1.0\end{array}$ & \multirow{6}{*}{$\begin{array}{l}\text { CNAE DOM } \\
1.0\end{array}$} \\
\hline $\begin{array}{l}\text { Acidentes } \\
\text { /doenças do } \\
\text { trabalho }(2000 \text { a } \\
2005) \\
\end{array}$ & CNAE 1.0 & $\begin{array}{c}\text { CNAE 1.0 X CNAE } 2.0 \\
\text { CNAE 2.0 X CNAE DOM } 2.0 \\
\text { CNAE DOM } 2.0 \text { X CNAE DOM } 1 .\end{array}$ & \\
\hline $\begin{array}{l}\text { Acidentes } \\
\text { /doenças do } \\
\text { trabalho }(2006 \text { a } \\
\text { 2016) }\end{array}$ & CNAE 2.0 & $\begin{array}{l}\text { CNAE 2.0 X CNAE DOM } 2.0 \\
\text { CNAE DOM 2.0 X CNAE DOM } 1.0\end{array}$ & \\
\hline $\begin{array}{l}\text { Censo } \\
\text { Demográfico } \\
2000\end{array}$ & $\begin{array}{l}\text { CNAE DOM } \\
1.0\end{array}$ & CNAE DOM 1.0 & \\
\hline $\begin{array}{l}\text { Censo } \\
\text { Demográfico } \\
2010\end{array}$ & $\begin{array}{l}\text { CNAE DOM } \\
2.0\end{array}$ & CNAE DOM 2.0 X CNAE DOM 1.0 & \\
\hline Qualidade & $\begin{array}{l}\text { NCM } 8 \\
\text { dígitos }\end{array}$ & $\begin{array}{c}\text { NCM } 8 \text { dig X CNAE } 2.0 \\
\text { CNAE 2.0 X CNAE DOM } 2.0 \\
\text { CNAE DOM 2.0 X CNAE DOM } 1.0\end{array}$ & \\
\hline
\end{tabular}

Fonte: Elaboração própria.

Nota: *CNAE DOM refere-se ao CNAE DOMICÍLIO, no qual o censo utiliza como referência.

A amostra do estudo é composta por 45 setores, como podem ser verificados no Apêndice Apêndice A. Observa-se na amostra que os estados e os setores foram expostos de maneira distinta ao aumento da concorrência de importações chinesas, sendo assim, torna-se válida a estratégia empírica utilizada no presente estudo. Os maiores índices, que correspondem aos setores mais expostos à concorrência de importação chinesa encontram-se nos setores de: "Fabricação de Material Eletrônico e de Aparelhos e Equipamentos de Comunicações"; "Fabricação de Máquinas, Aparelhos e Materiais Elétricos"; "Fabricação de Máquinas para Escritório e Equipamentos de Informática"; "Fabricação de Outros Equipamentos de Transporte"; "Fabricação de Máquinas e Equipamentos"; "Fabricação de Produtos Têxteis" e "Fabricação de Produtos Químicos".

No que se refere aos menores índices, que correspondem aos setores menos expostos a concorrência de importações chinesas, encontram-se os setores de: "Extração de Petróleo e Gás Natural e Serviços Relacionados"; "Fabricação de Produtos Alimentícios e Bebidas"; "Agricultura, Pecuária e Serviços Relacionados"; "Fabricação de Coque, Refino de Petróleo, Elaboração de Combustíveis Nucleares e Produção de Álcool"; "Fabricação de Artigos de Borracha e Plástico" e "Silvicultura, Exploração Florestal e Serviços Relacionados". Os mecanismos existentes e as evidências da literatura de comércio internacional e saúde/segurança do trabalhador, combinam-se para augurar que a concorrência de importações tem efeito nos acidentes e doenças do trabalho. 


\section{Resultados e discussões}

\subsection{O Efeito da Concorrência de Importações Chinesas sobre os Acidentes e Doenças do Trabalho no Brasil}

O surgimento da China como uma força importante na economia mundial é um dos maiores episódios econômicos ocorrido nos últimos anos, conforme elencam Costa et al. (2016). O padrão do comércio Brasil-China segue a mesma tendência de outros países em desenvolvimento, em que as exportações brasileiras para a China são cada vez mais produtos de setores agrícolas e extrativos, enquanto as importações brasileiras da China permanecem concentradas na manufatura. A rápida exposição brasileira ao comércio chinês sugere que as consequências no mercado de trabalho podem ter aumentado quando comparado a períodos anteriores ${ }^{12}$. Embora tenha havido significativa atenção aos impactos da globalização na desigualdade de renda, desigualdade educacional, desigualdade de gênero etc., apenas recentemente foi elaborada uma literatura que analisa o impacto da globalização na saúde do trabalhador.

A Tabela 2 relata os principais resultados para o efeito do choque da concorrência de importação chinesa sobre os acidentes e doenças do trabalho no Brasil, no período de 2000 a 2016. As três primeiras colunas fornecem as estimativas por meio do MQO e as colunas (4), (5) e (6) apresentam as estimativas do segundo estágio do MQ2E, conforme a equação (13). Os resultados do primeiro estágio encontram-se no Apêndice Apêndice C.

Com o intuito de avaliar se o aumento das importações advindas da China teve efeito nos acidentes e doenças do trabalho, dado a composição setorial de cada estado, os resultados encontrados estão apresentados na Tabela 2 . Tanto por meio do MQO quanto pelo MQ2E, o efeito foi positivo e significativo, indicando que o aumento da concorrência de importações chinesas aumentou os acidentes e doenças do trabalho no Brasil no período de 2000 a 2016. Analisando-se os dois modelos, destaca-se que nas colunas (1) e (4), considera-se apenas a variável explicativa de interesse, já nas colunas (2) e (5), considera-se a variável explicativa de interesse e um conjunto de efeitos fixos, e nas colunas (3) e (6), considera-se o modelo completo, incluindo as variáveis de controle.

Em observância à coluna (6), destaca-se que um aumento percentual na exposição brasileira a concorrência de importações chinesas aumentou em 5,5\% os acidentes e doenças do trabalho, no período de 2000 a 2016, tudo ou mais constante. Todas as estimativas apresentam o sinal positivo e significância estatística, demonstrando a robustez dos mesmos. Os resultados encontrados corroboram com os existentes na literatura. McManus \& Schaur (2016) evidenciaram em seus resultados que a concorrência de importações teve efeito significativo e positivo nos acidentes e doenças dos trabalhadores nas empresas de manufatura americanas.

Adda \& Fawaz (2020) destacaram que os choques de importação afetaram o emprego e a renda, mas apenas em áreas onde os empregos são mais intensos em tarefas rotineiras. Além disso, quando analisaram dados sobre saúde e mortalidade, elucidam que a concorrência de importação teve um efeito prejudicial na saúde física e mental, concentrado nas áreas mais expostas à concorrência de importação. Ademais, Colantone et al. (2019) descreveram em

\footnotetext{
${ }^{12}$ Como destacam os estudos de Benguria \& Ederington (2017) e Costa et al. (2016).
} 
Tabela 2: Estimativa do Efeito da Concorrência Chinesa sobre os Acidentes e Doenças do Trabalho

\begin{tabular}{l|lll|lll}
\hline \multirow{2}{*}{ MQO } & \multicolumn{3}{|c}{ MQ2E } \\
\cline { 2 - 7 } & $(1)$ & $(2)$ & $(3)$ & (4) & (5) & (6) \\
\hline
\end{tabular}

Variável dependente: $\log$ (Acidentes e Doenças do Trabalho)

\begin{tabular}{c|ccc|ccc}
\hline $\log \left(\begin{array}{c}\text { Concorrência } \\
\text { Chinesa) }\end{array}\right.$ & $3,847^{* * *}$ & $4,929^{* *}$ & $4,237^{* *}$ & $4,823^{* * *}$ & $6,308^{* * *}$ & $5,459^{* * *}$ \\
& $(0,869)$ & $(1,572)$ & $(1,061)$ & $(1,196)$ & $(1,867)$ & $(1,304)$ \\
& & & & & & \\
Idade & - & - & $-0,0384^{* *}$ & - & - & $-0,0386^{* * *}$ \\
& & & $(0,0101)$ & & & $(0,009)$ \\
Sexo (Masculino) & - & - & 0,186 & - & - & 0,209 \\
& & & $(0,172)$ & & & $(0,160)$ \\
Raça/Cor (Branco) & - & - & $-0,431$ & - & - & $-0,452$ \\
& & & $(0,354)$ & & & $(0,315)$ \\
Ocupação & - & - & $-0,972^{* * *}$ & - & - & $-0,955^{* * *}$ \\
& & & $(0,177)$ & & & $(0,157)$ \\
Escolaridade & - & - & 0,0333 & - & - & 0,0342 \\
& & & $(0,0307)$ & & & $(0,0274)$ \\
Estado Civil (Casado) & - & - & 0,205 & - & - & 0,178 \\
& & & $(0,258)$ & & & $(0,223)$ \\
Tamanho do & - & - & $0,248^{* * *}$ & - & - & $0,246^{* * *}$ \\
Estabelecimento & - & & $(0,0148)$ & & & $(0,0124)$ \\
\hline Controles & - & - & Sim & - & - & Sim \\
Efeitos fixos de estado & - & Sim & Sim & - & Sim & Sim \\
Efeitos fixos de setor & - & Sim & Sim & - & Sim & Sim \\
Efeitos fixos de ano & - & Sim & Sim & - & Sim & Sim \\
Observações & 14,975 & 14,975 & 14,975 & 14,975 & 14,975 & 14,975 \\
$R^{2}$ & 0,464 & 0,765 & 0,801 & 0,464 & 0,765 & 0,801 \\
\hline
\end{tabular}

Fonte: Resultado da pesquisa.

Notas: Todas as estimativas estão ponderadas pela população de cada estado no ano de 2000 (ano base);

${ }^{* * *} \mathrm{p}<0,01,{ }^{* *} \mathrm{p}<0,05,{ }^{*} \mathrm{p}<0,1$ indicam níveis de significância de $1 \%, 5 \%$ e $10 \%$,

respectivamente; Erros-padrão robustos e clusterizados em nível de macrorregião (Norte, Sul, Sudeste, Nordeste e Centro-Oeste) estão entre parênteses. Em todas as estimativas controla-se por Tendências Específicas de Estados. Variáveis de controle consideradas: idade, sexo, raça, ocupação, escolaridade, estado civil e tamanho do estabelecimento. 
seus resultados que a concorrência de importação teve um grande impacto negativo sobre a saúde mental dos indivíduos.

De acordo com McManus \& Schaur (2016), as taxas de lesões nas indústrias concorrentes dos EUA aumentam a curto e médio prazo, particularmente em estabelecimentos menores. Nesse sentido, conforme explanado na metodologia, foi feita a diferenciação em relação ao tempo. Na Tabela 3, apresentam-se os resultados, em que pode-se verificar que todos os resultados são positivos e significativos, indicando que a concorrência de importações chinesas aumentou os acidentes e doenças do trabalho no Brasil nos diferentes períodos considerados. No entanto, a magnitude do efeito é maior no curto e médio prazo.

Verificando-se a magnitude do efeito, nota-se que até 2010 (diferenciação de 6 anos), o efeito da concorrência de importação chinesa nos acidentes e doenças do trabalho era inferior a 9\%. Os anos de 2000-2009 e 2000-2008 apresentam um efeito maior. Posteriormente, considerando a diferenciação de 9 até 12 anos (2000-2007 a 2000-2004), nota-se que a magnitude do efeito é muito expressiva. Conforme McManus \& Schaur (2016) destacam, espera-se que no longo prazo (nesse estudo é o período maior de análise, ou seja, que contém mais anos) as diferenças regulatórias, a heterogeneidade dos trabalhadores, a atualização tecnológica, dentre outros fatores, façam com que as empresas/setores se ajustem, tornando-se mais sólidas diante da concorrência de importações estrangeiras.

Com a finalidade de analisar se o aumento da concorrência de importações chinesas afetou de maneira diferente os acidentes e doenças do trabalho em setores com maior e menor número de empregados, os resultados encontrados estão apresentados na Tabela 4. Foram considerados diferentes quartis de trabalhadores $(0,25 ; 0,50 ; 0,75$ e 1,0$)$, com a intenção de verificar se o efeito é maior em setores com menor número de empregados, ou seja, nos menores quartis (menores estabelecimentos). Observa-se por meio dos quartis, que todos os resultados encontrados foram positivos e significativos, demonstrando que o aumento da concorrência de importações chinesas aumentou os acidentes e doenças do trabalho. Destaca-se que o maior efeito é verificado nos quartis $\mathrm{Q}(0,25)$ e $\mathrm{Q}(0,50)$, nos quais se encontram os setores que possuem o menor número de trabalhadores em comparação aos quartis $\mathrm{Q}(0,75)$ e $\mathrm{Q}(1,0)$. Nesse sentido, os resultados vão ao encontro do que a literatura sugere, setores com menor número de empregados sofrem um maior efeito da concorrência de importações, em que, em empresas menores, um aumento na concorrência de importações diminui o custo esperado de uma lesão e induz essas empresas a atuarem com taxas de lesões mais altas (McManus \& Schaur 2016).

McManus \& Schaur (2016) demonstraram em seus resultados que a concorrência de importações tem impacto significativo e positivo nos acidentes e doenças dos trabalhadores e, que o efeito é maior em empresas menores ${ }^{13}$. As empresas menores e menos produtivas, são afetadas de modo negativo pela concorrência de importações e tendem a sair do mercado ${ }^{14}$. Uma maior probabilidade de sair do mercado alude que as empresas têm menos chances de

\footnotetext{
${ }^{13}$ Os autores estimaram o efeito marginal, levando em consideração, aproximadamente o $10^{\circ}$ percentil (empresas com 40 trabalhadores), mediana (empresas com 100 trabalhadores) e o $90^{\circ}$ percentil (empresas com 400 trabalhadores). Os efeitos são positivos e significativos em empresas com menos de 250 trabalhadores, no entanto, os efeitos não são significativos para empresas com maior número de trabalhadores.

${ }^{14}$ Como pode ser visto em Bernard et al. (2006a,b), Melitz (2003) e Pavcnik (2002).
} 
Tabela 3: Estimativa do Efeito da Concorrência Chinesa sobre os Acidentes e Doenças do Trabalho considerando a diferenciação em relação ao tempo

\begin{tabular}{l|llllll}
\hline \multicolumn{5}{c}{ MQ2E } \\
\hline $\begin{array}{l}\text { Diferenciação em } \\
\text { relação ao tempo }\end{array}$ & (1 ano) & (2 anos) & (3 anos) & (4 anos) & (5 anos) & (6 anos) \\
\hline
\end{tabular}

Variável dependente: $\log$ (Acidentes e Doenças do Trabalho)

\begin{tabular}{|c|c|c|c|c|c|c|}
\hline & $\begin{array}{l}2000 \\
2015 \\
\end{array}$ & $\begin{array}{l}2000 \\
2014 \\
\end{array}$ & $\begin{array}{l}2000 \\
2013 \\
\end{array}$ & $\begin{array}{l}2000 \\
2012 \\
\end{array}$ & $\begin{array}{l}2000 \\
2011 \\
\end{array}$ & $\begin{array}{l}2000 \\
2010 \\
\end{array}$ \\
\hline $\begin{array}{c}\log (\text { Concorrência } \\
\text { Chinesa })\end{array}$ & $\begin{array}{l}6,139^{* * *} \\
(1,371)\end{array}$ & $\begin{array}{l}6,389^{* * *} \\
(1,383)\end{array}$ & $\begin{array}{l}6,875^{* * *} \\
(1,497)\end{array}$ & $\begin{array}{c}7,437^{* * *} \\
(1,618)\end{array}$ & $\begin{array}{l}7,792^{* * *} \\
(1,753)\end{array}$ & $\begin{array}{l}8,734^{* * *} \\
(2,006)\end{array}$ \\
\hline $\begin{array}{c}\text { Observações } \\
\mathrm{R}^{2}\end{array}$ & $\begin{array}{c}14,109 \\
0,803\end{array}$ & $\begin{array}{c}13,247 \\
0,803\end{array}$ & $\begin{array}{c}12,382 \\
0,803\end{array}$ & $\begin{array}{c}11,486 \\
0,804\end{array}$ & $\begin{array}{c}10,616 \\
0,804\end{array}$ & $\begin{array}{l}9,728 \\
0,803\end{array}$ \\
\hline $\begin{array}{l}\text { Diferenciação em } \\
\text { relação ao tempo }\end{array}$ & (7 anos) & (8 anos) & (9 anos) & (10 anos) & (11 anos) & (12 anos) \\
\hline & $\begin{array}{l}2000 \\
2009\end{array}$ & $\begin{array}{l}2000 \\
2008\end{array}$ & $\begin{array}{l}2000 \\
2007\end{array}$ & $\begin{array}{l}2000 \\
2006\end{array}$ & $\begin{array}{l}2000 \\
2005\end{array}$ & $\begin{array}{l}2000 \\
2004\end{array}$ \\
\hline $\begin{array}{c}\log (\text { Concorrência } \\
\text { Chinesa })\end{array}$ & $\begin{array}{l}10,10^{* * *} \\
(2,459)\end{array}$ & $\begin{array}{l}12,48^{* * *} \\
(3,083)\end{array}$ & $\begin{array}{l}23,40^{* * *} \\
(4,631)\end{array}$ & $\begin{array}{l}27,82^{* * *} \\
(5,652)\end{array}$ & $\begin{array}{l}39,54^{* * *} \\
(8,322)\end{array}$ & $\begin{array}{l}41,63^{* * *} \\
(11,55)\end{array}$ \\
\hline $\begin{array}{c}\text { Controles } \\
\text { Efeitos fixos de estado } \\
\text { Efeitos fixos de setor } \\
\text { Efeitos fixos de ano } \\
\text { Observações } \\
\mathrm{R}^{2}\end{array}$ & $\begin{array}{l}\text { Sim } \\
\text { Sim } \\
\text { Sim } \\
\text { Sim } \\
8,801 \\
0,803\end{array}$ & $\begin{array}{l}\text { Sim } \\
\text { Sim } \\
\text { Sim } \\
\text { Sim } \\
7,910 \\
0,805\end{array}$ & $\begin{array}{l}\text { Sim } \\
\text { Sim } \\
\text { Sim } \\
\text { Sim } \\
6,998 \\
0,807\end{array}$ & $\begin{array}{l}\text { Sim } \\
\text { Sim } \\
\text { Sim } \\
\text { Sim } \\
6,102 \\
0,809\end{array}$ & $\begin{array}{l}\text { Sim } \\
\text { Sim } \\
\text { Sim } \\
\text { Sim } \\
5,209 \\
0,812\end{array}$ & $\begin{array}{l}\text { Sim } \\
\text { Sim } \\
\text { Sim } \\
\text { Sim } \\
4,348 \\
0,812\end{array}$ \\
\hline
\end{tabular}

Fonte: Resultado da pesquisa.

Notas: Todas as estimativas estão ponderadas pela população de cada estado no ano de 2000 (ano base);

${ }^{* * *} \mathrm{p}<0,01,{ }^{* *} \mathrm{p}<0,05,{ }^{*} \mathrm{p}<0,1$ indicam níveis de significância de $1 \%, 5 \%$ e $10 \%$, respectivamente;

Erros-padrão robustos e clusterizados em nível de macrorregião (Norte, Sul, Sudeste, Nordeste e Centro-Oeste) estão entre parênteses. Em todas as estimativas controla-se por Tendências Específicas de Estados. Variáveis de controle consideradas: idade, sexo, raça, ocupação, escolaridade, estado civil e tamanho do estabelecimento 
Tabela 4: Estimativa do Efeito da Concorrência Chinesa sobre os Acidentes e Doenças do Trabalho considerando diferentes tamanhos de estabelecimento (por quartil)

\begin{tabular}{l|llll}
\hline \multicolumn{5}{c}{ MQ2E } \\
\hline & $Q(0,25)$ & $Q(0,50)$ & $Q(0,75)$ & $Q(1,0)$ \\
\hline
\end{tabular}

Variável dependente: $\log$ (Acidentes e Doenças do Trabalho)

\begin{tabular}{c|cccc}
\hline & & & & \\
$\log ($ Concorrência Chinesa $)$ & $18,85^{* * *}$ & $10,42^{* * *}$ & $4,280^{*}$ & $4,626^{* * *}$ \\
& $(3,357)$ & $(2,024)$ & $(2,109)$ & $(0,842)$ \\
& & & & \\
\hline Controles & Sim & Sim & Sim & Sim \\
Efeitos fixos de estado & Sim & Sim & Sim & Sim \\
Efeitos fixos de setor & Sim & Sim & Sim & Sim \\
Efeitos fixos de ano & Sim & Sim & Sim & Sim \\
Observações & 3,741 & 3,744 & 3,741 & 3,749 \\
$\mathrm{R}^{2}$ & 0,788 & 0,811 & 0,826 & 0,806 \\
\hline
\end{tabular}

Fonte: Resultado da pesquisa.

Notas: Todas as estimativas estão ponderadas pela população de cada estado no ano de 2000 (ano base);

${ }^{* * *} \mathrm{p}<0,01,{ }^{* *} \mathrm{p}<0,05,{ }^{*} \mathrm{p}<0,1$ indicam níveis de significância de $1 \%, 5 \%$ e

$10 \%$, respectivamente;

Erros-padrão robustos e clusterizados em nível de macrorregião (Norte, Sul, Sudeste, Nordeste e Centro-Oeste) estão entre parênteses. Em todas as estimativas controla-se por Tendências Específicas de Estados. Variáveis de controle consideradas: idade, sexo, raça, ocupação, escolaridade, estado civil e tamanho do estabelecimento.

serem responsáveis por custos futuros, como indenizações e perdas de produtividade, relacionados às lesões que acontecem hoje.

Com o desígnio de verificar se o efeito do aumento das importações chinesas no Brasil no período de 2000 a 2016 sobre os acidentes e doenças do trabalho, difere-se entre os setores comercializáveis, que competem diretamente com as importações chinesas e, os setores não comercializáveis, que não competem diretamente com as importações chinesas, os resultados encontrados estão apresentados na Tabela 5. Foram considerados nessa análise, os setores comercializáveis e os setores não comercializáveis, conforme Dix-Carneiro \& Kovak (2017). No Apêndice Apêndice A, demonstram-se os setores considerados em cada estimativa.

$\mathrm{Na}$ Tabela 5, nota-se que nas colunas (3) e (4), quando considera-se os setores comercializáveis, o efeito encontrado é positivo e significativo. Demonstrando que para esses setores, o aumento da concorrência de produtos chineses aumentou os acidentes e doenças do trabalho no Brasil no período de análise considerado. No entanto, quando verifica-se os setores não comercializáveis, colunas (5) e (6), observa-se que os mesmos não possuem significância estatística, ou seja, a concorrência de importações chinesas não afetou os acidentes e doenças do trabalho nesses setores. O que já era de se esperar, dado que esses setores não competem diretamente com produtos advindos da China, e que conforme a literatura sugere, espera-se que o efeito da concorrência chinesa seja maior em setores que competem diretamente com os produtos importados. 
Tabela 5: Estimativa do Efeito da Concorrência Chinesa sobre os Acidentes e Doenças do Trabalho considerando setores comercializáveis e não comercializáveis

\begin{tabular}{|c|c|c|c|c|c|c|}
\hline & $\begin{array}{c}\text { (1) } \\
\text { MQO }\end{array}$ & $\begin{array}{c}(2) \\
\text { MQ2E }\end{array}$ & $\begin{array}{c}(3) \\
\text { MQO }\end{array}$ & $\begin{array}{c}(4) \\
\text { MQ2E }\end{array}$ & $\begin{array}{c}(5) \\
\text { MQO }\end{array}$ & $\begin{array}{c}(6) \\
M Q 2 E\end{array}$ \\
\hline \multicolumn{7}{|c|}{ Variável dependente: $\log$ (Acidentes e Doenças do Trabalho) } \\
\hline $\log ($ Concorrência Chinesa) & $\begin{array}{l}4,237^{* *} \\
(1,061)\end{array}$ & $\begin{array}{c}5,459^{* * *} \\
(1,304)\end{array}$ & $\begin{array}{l}4,164^{* *} \\
(1,061)\end{array}$ & $\begin{array}{c}5,384^{* * *} \\
(1,308)\end{array}$ & $\begin{array}{c}37,04 \\
(30,29)\end{array}$ & $\begin{array}{c}266,3 \\
(201,3)\end{array}$ \\
\hline Setores & \multicolumn{2}{|c|}{ Todos } & \multicolumn{2}{|c|}{ Comercializável } & \multicolumn{2}{|c|}{ Não Comercializável } \\
\hline Controles & Sim & Sim & Sim & Sim & Sim & Sim \\
\hline Efeitos fixos de estado & Sim & Sim & Sim & Sim & Sim & Sim \\
\hline Efeitos fixos de setor & $\operatorname{Sim}$ & Sim & Sim & $\operatorname{Sim}$ & Sim & Sim \\
\hline Efeitos fixos de ano & Sim & Sim & Sim & Sim & Sim & Sim \\
\hline Observações & 14,975 & 14,975 & 14,007 & 14,007 & 968 & 968 \\
\hline $\mathrm{R}^{2}$ & 0,801 & 0,801 & 0,798 & 0,797 & 0,972 & 0,971 \\
\hline
\end{tabular}

Fonte: Resultado da pesquisa

Notas: Todas as estimativas estão ponderadas pela população de cada estado no ano de 2000 (ano base); ${ }^{* * *} \mathrm{p}<0,01,{ }^{* *} \mathrm{p}<0,05,{ }^{*} \mathrm{p}<0,1$ indicam níveis de significância de $1 \%, 5 \%$ e $10 \%$, respectivamente;

Erros-padrão robustos e clusterizados em nível de macrorregião (Norte, Sul, Sudeste, Nordeste e

Centro-Oeste) estão entre parênteses. Em todas as estimativas controla-se por Tendências Específicas

de Estados. Variáveis de controle consideradas: idade, sexo, raça, ocupação, escolaridade, estado civil e tamanho do estabelecimento. 


\subsection{Mecanismo}

Em relação ao mecanismo considerado, quando analisa-se a renda, espera-se encontrar um efeito negativo do aumento da concorrência de importações chinesas sobre a renda dos trabalhadores brasileiros. Sendo assim, foram considerados três tipos de rendas e em todas elas verifica-se um efeito negativo da concorrência de importações chinesas sobre a renda dos trabalhadores brasileiros no período de 2000 a 2016. Na Tabela 6, demonstram-se os resultados de todas as especificações. Na primeira parte da tabela, destaca-se o Total de Rendimentos no Trabalho Principal em Salários Mínimos, em que todas as estimativas apresentam o sinal negativo e significância estatística. Analisandose a coluna (6), destaca-se que um aumento percentual na exposição brasileira a concorrência de importações chinesas reduziu em média 1,069\% a renda dos trabalhadores, no período de 2000 a 2016, tudo ou mais constante.

$\mathrm{Na}$ segunda parte da tabela, considerou-se o Total de Rendimentos em Todos os Trabalhos em Salários Mínimos, em que se observa um comportamento similar ao destacado anteriormente. E na terceira parte da tabela, em que estimou-se o Total de Rendimentos em Todos os Trabalhos, deflacionando pelo IGP-DI para o ano de 2016, todas as especificações apresentam sinal negativo da concorrência de importações chinesas sobre a renda dos brasileiros. Analisando a coluna (6), destaca-se que um aumento percentual na exposição brasileira a concorrência de importações chinesas reduziu em média $0,376 \%$ a renda dos trabalhadores, no período de 2000 a 2016, tudo ou mais constante.

Destaca-se que o aumento da concorrência de importação chinesa levou a uma variação negativa na renda dos brasileiros, que pode ser explicada pela pauta de importação brasileira advinda da China ser composta de produtos manufaturados e que esses produtos de menor preço entram no país competindo com os produtos nacionais. Em muitas vezes, os setores não têm poder de barganha para competir com esses produtos e, para permanecer do mercado, necessitam de ajustes em suas empresas e um desses acertes é o salário dos trabalhadores. Essa relação negativa entre concorrência de importações chinesas e renda também é encontrada por Benguria \& Ederington (2017) e Costa et al. (2016), para o cenário brasileiro.

De acordo com Benguria \& Ederington (2017), o aumento da concorrência de importações levou a uma redução na renda média dos brasileiros. No entanto, os autores destacaram que o aumento de importações de produtos chineses pelo Brasil é explicado quase que totalmente pelo efeito na renda dos trabalhadores do sexo masculino. Costa et al. (2016) examinaram as mudanças nos resultados do mercado de trabalho das regiões produtoras de manufaturas afetadas pelo aumento da oferta chinesa de produtos. E encontraram que as regiões que competem diretamente com as importações chinesas, apresentam um crescimento mais lento dos salários no setor de manufatura.

\subsection{Robustez}

Em relação à qualidade das exportações, na Tabela 7 , regride-se o choque de concorrência de importações chinesas sobre os acidentes e doenças do trabalhado, na qual a amostra foi dividida por quartis de qualidade das exportações. Foram feitas as estimativas tanto por MQO como por MQ2E, considerando diferentes especificações, como pode ser verificado. A especificação preferida é a coluna (6) de cada quartil, em que se considera o modelo completo, ou 
Tabela 6: Mecanismo de Renda

\begin{tabular}{l|lll|lll}
\hline & \multicolumn{3}{|c|}{ MQO } & \multicolumn{3}{c}{ MQ2E } \\
\cline { 2 - 6 } & $(1)$ & $(2)$ & $(3)$ & $(4)$ & (5) & (6) \\
\hline
\end{tabular}

Variável dependente: log (Total de Rendimentos no Trabalho Principal em Salários Mínimos)

\begin{tabular}{c|ccc|ccc}
\hline & & & & & & \\
$\log ($ Concorrência Chinesa $)$ & $-0,701^{*}$ & $-0,981^{* *}$ & $-0,775^{* *}$ & $-1,114^{* *}$ & $-1,103^{* * *}$ & $-1,069^{* * *}$ \\
& $(0,296)$ & $(0,257)$ & $(0,183)$ & $(0,454)$ & $(0,232)$ & $(0,188)$ \\
Observações & 13,371 & 13,371 & 13,371 & 13,371 & 13,371 & 13,371 \\
$\mathrm{R}^{2}$ & 0,643 & 0,703 & 0,750 & 0,643 & 0,703 & 0,750 \\
\hline
\end{tabular}

Variável dependente: $\log$ ( Total de Rendimentos em Todos os Trabalhos em Salários Mínimos)

\begin{tabular}{c|ccc|ccc}
\hline & & & & & & \\
$\log ($ Concorrência Chinesa) $)$ & $-0,821^{* *}$ & $-1,079^{*}$ & $-0,869^{*}$ & $-1,178^{* * *}$ & $-1,111^{* * *}$ & $-1,071^{* * *}$ \\
& $(0,271)$ & $(0,415)$ & $(0,350)$ & $(0,439)$ & $(0,335)$ & $(0,291)$ \\
& & & & & & \\
Observações & 13,334 & 13,334 & 13,334 & 13,334 & 13,334 & 13,334 \\
$\mathrm{R}^{2}$ & 0,652 & 0,712 & 0,761 & 0,651 & 0,712 & 0,761 \\
\hline
\end{tabular}

Variável dependente: $\log$ (Total de Rendimentos em Todos os Trabalhos ${ }^{\#}$ )

\begin{tabular}{c|ccc|ccc}
\hline & & & & & & \\
$\log$ (Concorrência Chinesa) $)$ & $-0,181$ & $-0,221$ & $-0,129$ & $-0,572^{* *}$ & $-0,352^{* *}$ & $-0,376^{* *}$ \\
& $(0,226)$ & $(0,140)$ & $(0,108)$ & $(0,236)$ & $(0,178)$ & $(0,155)$ \\
Observações & 14,721 & 14,721 & 14,721 & 14,721 & 14,721 & 14,721 \\
$\mathrm{R}^{2}$ & 0,526 & 0,686 & 0,760 & 0,526 & 0,686 & 0,760 \\
\hline Controles & - & - & Sim & - & - & Sim \\
Efeitos fixos de estado & - & Sim & Sim & - & Sim & Sim \\
Efeitos fixos de setor & - & Sim & Sim & - & Sim & Sim \\
Efeitos fixos de ano & - & Sim & Sim & - & Sim & Sim \\
\hline
\end{tabular}

Fonte: Resultado da pesquisa.

Notas: Todas as estimativas estão ponderadas pela população de cada estado no ano de 2000 (ano base);

${ }^{* * *} \mathrm{p}<0,01,{ }^{* *} \mathrm{p}<0,05,{ }^{*} \mathrm{p}<0,1$ indicam níveis de significância de $1 \%, 5 \%$ e $10 \%$, respectivamente;

Erros-padrão robustos e clusterizados em nível de macrorregião (Norte, Sul, Sudeste, Nordeste e Centro-Oeste) estão entre parênteses. Em todas as estimativas controla-se por Tendências Específicas de Estados. Variáveis de controle consideradas: idade, sexo, raça, ocupação, escolaridade, estado civil e tamanho do estabelecimento. Todas as rendas consideradas estão em sua forma lagarítmica. \#A renda está deflacionada pelo IGP-DI para o ano de 2016.

seja, com efeitos fixos e controle. Conforme a literatura destaca, empresas menores têm maior probabilidade de serem afetadas pela concorrência de importações não apenas pelo fato de serem menos produtivas, mas também porque produzem bens de menor qualidade. Segundo Bastos \& Silva (2010) e Verhoogen (2008), as empresas mais produtivas exportarão produtos de melhor qualidade. E, para manter a qualidade elevada, as empresas necessitam pagar melhores salários a fim de garantir uma mão de obra mais qualificada.

Nesse sentido, espera-se que os menores quartis de qualidade apresentem os maiores efeitos do aumento da concorrência de importação chinesa sobre os acidentes e doenças do trabalho. Se a atualização da qualidade estiver associada à segurança do local de trabalho, esses ajustes de equilíbrio podem afetar as estimativas, conforme destacam McManus \& Schaur (2016). Sendo assim, de acordo com a Tabela 7, pode-se verificar que os setores com menor qualidade nos seus produtos, menores quartis $(\mathrm{Q} 0,25, \mathrm{Q} 0,50$ e $\mathrm{Q} 0,75)$, sen- 
tem mais o efeito da concorrência de importações chinesas sobre os acidentes e doenças do trabalho, em comparação maior quartil $(\mathrm{Q} 1,0)$, conforme sugere a literatura.

McManus \& Schaur (2016) trazem que os setores com menos trabalhadores, possuem menos produtividade e fornecem produtos com menor qualidade. Ademais, as empresas respondem à concorrência de importação melhorando a qualidade dos produtos e investindo em novas tecnologias. Para examinar isso, divide-se a amostra por diferentes percentis de qualidade das exportações. Ou seja, a amostra foi dividida considerando a qualidade abaixo do percentil 75 (Qualidade $\leq 75$ Percentil) e acima do percentil 75 (Qualidade $>75$ Percentil). A Tabela 8 demonstra os resultados, em que se verifica que, dos setores que compõem a amostra, a maioria se enquadra abaixo do percentil 75 .

Analisando-se os setores com Qualidade $\leq 75$ Percentil, verifica-se que o efeito da concorrência de importações sobre os acidentes e doenças do trabalho é maior em setores que possuem menos trabalhadores (menor tamanho de estabelecimento), ou seja, os menores quartis $(\mathrm{Q}(0,25)$ e $\mathrm{Q}(0,50))$, conforme a literatura sugere, em que os setores com menor número de empregados e menor qualidade nos seus produtos tendem a sofrer mais o efeito da concorrência estrangeira sobre os acidentes e doenças do trabalho. No que tange ao maior percentil de qualidade (Qualidade > 75 Percentil) conforme McManus \& Schaur (2016), espera-se novamente que, mesmo enquadrados em um percentil maior da qualidade das exportações dos seus produtos, os setores com menor número de empregados tendem a sofrer mais o efeito da concorrência de importações chinesas. Os resultados encontrados demonstraram esse comportamento, como pode ser verificado na Tabela 8.

Os resultados aqui encontrados mostram que os efeitos da concorrência das importações chinesas sobre os acidentes e doenças do trabalho são um canal importante a ser considerado para o bem-estar geral e entre os trabalhadores dos diferentes setores da economia brasileira. Todos os resultados encontrados corroboram com a literatura existente ${ }^{15}$. Nesse sentido, destaca-se a importância de políticas públicas e programas com o objetivo de minimizar os efeitos negativos causados na saúde do trabalhador. Dada a entrada expressiva de produtos com menor preço no mercado brasileiro e, com isso, a necessidade de um maior esforço do trabalhador, bem como das empresas/setores, para tentar competir com esses produtos, na tentativa de permanecer atuando no mercado.

\section{Principais conclusões}

Este estudo teve como principal objetivo analisar a relação entre acidentes e doenças do trabalho ocorridos no Brasil e o aumento da concorrência de importação da China, no período de 2000 a 2016. Os resultados encontrados demonstram que o aumento da concorrência de importações chinesas aumentou os acidentes e doenças do trabalho no Brasil no período de 2000 a 2016. Além disso, a magnitude do efeito é maior no curto e médio prazo. Ademais, observa-se que o maior efeito da concorrência de importações chinesas na saúde do trabalhador é verificado nos setores que possuem o menor

\footnotetext{
${ }^{15}$ Benguria \& Ederington (2017), McManus \& Schaur (2016), Costa et al. (2016) e Hummels et al. (2015).
} 
Tabela 7: Estimativa do Efeito da Concorrência Chinesa sobre os Acidentes e Doenças do Trabalho considerando diferentes quartis de qualidade das exportações

\begin{tabular}{|c|c|c|c|c|c|c|c|c|c|c|c|c|}
\hline & \multicolumn{3}{|c|}{ MQO } & \multicolumn{3}{|c|}{ MQ2E } & \multicolumn{3}{|c|}{ MQO } & \multicolumn{3}{|c|}{ MQ2E } \\
\hline & $(1)$ & $(2)$ & (3) & (4) & (5) & (6) & (1) & $(2)$ & $(3)$ & $(4)$ & (5) & $(6)$ \\
\hline \multicolumn{13}{|c|}{ Variável dependente: $\log$ (Acidentes e Doenças do Trabalho) } \\
\hline \multicolumn{13}{|c|}{ Amostra dividida por Quartil de Qualidade das Exportações } \\
\hline & \multicolumn{6}{|c|}{$\mathrm{Q}(0.25)$} & \multicolumn{6}{|c|}{$\mathrm{Q}(0.50)$} \\
\hline $\begin{array}{c}\log (\text { Concorrência } \\
\text { Chinesa })\end{array}$ & $\begin{array}{l}13,78^{* * *} \\
(2,303)\end{array}$ & $\begin{array}{c}16,47^{* * *} \\
(2,790)\end{array}$ & $\begin{array}{l}10,25^{* *} \\
(2,332)\end{array}$ & $\begin{array}{l}15,95^{* * *} \\
(2,327)\end{array}$ & $\begin{array}{c}18,44^{* * *} \\
(3,126)\end{array}$ & $\begin{array}{c}11,01^{* * *} \\
(2,850)\end{array}$ & $\begin{array}{l}10,15^{* * *} \\
(1,759)\end{array}$ & $\begin{array}{l}13,58^{* * *} \\
(2,469)\end{array}$ & $\begin{array}{c}7,078^{* * *} \\
(0,793)\end{array}$ & $\begin{array}{l}11,65^{* * *} \\
(2,103)\end{array}$ & $\begin{array}{l}17,24^{* * *} \\
(2,033)\end{array}$ & $\begin{array}{l}9,135^{* * *} \\
(0,913)\end{array}$ \\
\hline Observações & 3,914 & 3,914 & 3,914 & 3,914 & 3,914 & 3,914 & 3,910 & 3,910 & 3,910 & 3,910 & 3,910 & 3,910 \\
\hline $\mathrm{R}^{2}$ & 0,327 & 0,472 & 0,630 & 0,327 & 0,472 & 0,630 & 0,292 & 0,452 & 0,665 & 0,292 & 0,451 & 0,664 \\
\hline & \multicolumn{6}{|c|}{$Q(0.75)$} & \multicolumn{6}{|c|}{$Q(1.0)$} \\
\hline $\begin{array}{c}\log (\text { Concorrência } \\
\text { Chinesa })\end{array}$ & $\begin{array}{l}7,933^{* *} \\
(2,720)\end{array}$ & $\begin{array}{l}14,36^{* *} \\
(3,231)\end{array}$ & $\begin{array}{c}7,631^{* * *} \\
(1,298)\end{array}$ & $\begin{array}{l}10,57^{* * *} \\
(3,682)\end{array}$ & $\begin{array}{l}20,35^{* * *} \\
(2,870)\end{array}$ & $\begin{array}{c}10,32^{* * *} \\
(1,503)\end{array}$ & $\begin{array}{l}5,701^{* *} \\
(1,793)\end{array}$ & $\begin{array}{l}8,895^{* *} \\
(2,109)\end{array}$ & $\begin{array}{l}4,371^{* *} \\
(1,118)\end{array}$ & $\begin{array}{l}7,007^{* * *} \\
(2,170)\end{array}$ & $\begin{array}{l}11,10^{* * *} \\
(2,278)\end{array}$ & $\begin{array}{l}5,367^{* * *} \\
(1,255)\end{array}$ \\
\hline Observações & 3,911 & 3,911 & 3,911 & 3,911 & 3,911 & 3,911 & 3,894 & 3,894 & 3,894 & 3,894 & 3,894 & 3,894 \\
\hline $\mathrm{R}^{2}$ & 0,255 & 0,455 & 0,682 & 0,253 & 0,451 & 0,681 & 0,236 & 0,448 & 0,696 & 0,234 & 0,445 & 0,695 \\
\hline Controles & - & - & Sim & - & - & Sim & - & - & Sim & - & - & Sim \\
\hline Efeitos fixos de estado & - & Sim & Sim & - & Sim & Sim & - & Sim & Sim & - & Sim & Sim \\
\hline Efeitos fixos de setor & - & Sim & Sim & - & Sim & Sim & - & Sim & Sim & - & Sim & Sim \\
\hline Efeitos fixos de ano & - & Sim & Sim & - & Sim & Sim & - & Sim & Sim & - & Sim & Sim \\
\hline
\end{tabular}

Fonte: Resultado da pesquisa.

Notas: Todas as estimativas estão ponderadas pela população de cada estado no ano de 2000 (ano base)

*** $\mathrm{p}<0,01,{ }^{* *} \mathrm{p}<0,05,{ }^{*} \mathrm{p}<0,1$ indicam níveis de significância de $1 \%, 5 \%$ e $10 \%$, respectivamente;

Erros-padrão robustos e clusterizados em nível de macrorregião (Norte, Sul, Sudeste, Nordeste e Centro-Oeste) estão entre parênteses. Em todas as estimativas controla-se por Tendências Específicas de Estados. Variáveis de controle consideradas: idade, sexo, raça, ocupação, escolaridade, estado civil e tamanho de estabelecimento. 
Tabela 8: Estimativa do Efeito da Concorrência Chinesa sobre os Acidentes e Doenças do Trabalho considerando diferentes quartis de qualidade das exportações e tamanho de estabelecimento

\begin{tabular}{l|llll|llll}
\hline \multicolumn{10}{|c}{ MQ2E } \\
\hline & $(1)$ & $(2)$ & $(3)$ & $(4)$ & $(5)$ & $(6)$ & $(7)$ & $(8)$ \\
\hline
\end{tabular}

Variável dependente: $\log$ (Acidentes e Doenças do Trabalho)

\begin{tabular}{|c|c|c|c|c|c|c|c|c|}
\hline Qualidade & \multicolumn{4}{|c|}{ Qualidade $\leq 75$ Percentil } & \multicolumn{4}{|c|}{ Qualidade $>75$ Percentil } \\
\hline Tamanho Estabelecimento & $\mathrm{Q}(0,25)$ & $\mathrm{Q}(0,50)$ & $\mathrm{Q}(0,75)$ & $\mathrm{Q}(1,0)$ & $\mathrm{Q}(0,25)$ & $\mathrm{Q}(0,50)$ & $\mathrm{Q}(0,75)$ & $\mathrm{Q}(1,0)$ \\
\hline $\begin{array}{c}\log (\text { Concorrência } \\
\text { Chinesa })\end{array}$ & $\begin{array}{l}37,12^{* * *} \\
(2,142)\end{array}$ & $\begin{array}{l}22,65^{* * *} \\
(1,856)\end{array}$ & $\begin{array}{l}13,35^{* * *} \\
(2,977)\end{array}$ & $\begin{array}{l}5,756^{* * *} \\
(1,651)\end{array}$ & $\begin{array}{l}21,37^{* * *} \\
(4,541)\end{array}$ & $\begin{array}{l}9,162^{* *} \\
(3,727)\end{array}$ & $\begin{array}{c}5,672^{* * *} \\
(1,678)\end{array}$ & $\begin{array}{c}5,957^{* * *} \\
(1,014)\end{array}$ \\
\hline Observações & 2,919 & 2,993 & 2,948 & 2,875 & 986 & 914 & 956 & 1,038 \\
\hline $\mathrm{R}^{2}$ & 0,713 & 0,669 & 0,670 & 0,642 & 0,815 & 0,775 & 0,783 & 0,749 \\
\hline Controles & Sim & Sim & Sim & Sim & Sim & Sim & Sim & Sim \\
\hline Efeitos fixos de estado & Sim & Sim & Sim & Sim & Sim & Sim & Sim & Sim \\
\hline Efeitos fixos de setor & Sim & Sim & Sim & Sim & Sim & Sim & Sim & Sim \\
\hline Efeitos fixos de ano & Sim & Sim & Sim & Sim & Sim & Sim & Sim & Sim \\
\hline
\end{tabular}

Fonte: Resultado da pesquisa.

Notas: Todas as estimativas estão ponderadas pela população de cada estado no ano de 2000 (ano base);

${ }^{* * *} \mathrm{p}<0,01,{ }^{* *} \mathrm{p}<0,05,{ }^{*} \mathrm{p}<0,1$ indicam níveis de significância de $1 \%, 5 \%$ e $10 \%$, respectivamente;

Erros-padrão robustos e clusterizados em nível de macrorregião (Norte, Sul, Sudeste, Nordeste e Centro-Oeste) estão entre

parênteses. Em todas as estimativas controla-se por Tendências Específicas de Estados. Variáveis de controle consideradas:

idade, sexo, raça, ocupação, escolaridade, estado civil e tamanho de estabelecimento. 
número de trabalhadores. Considerou-se também diferentes setores, sendo eles setores comercializáveis e setores não comercializáveis, em que se verifica nos setores comercializáveis, um efeito positivo e significativo, demonstrando que para esses setores, o aumento da concorrência de produtos chineses afetou positivamente os acidentes e doenças do trabalho no Brasil no período de análise considerado. Já para os setores não comercializáveis, observa-se que os resultados não apresentam significância estatística.

No que tange ao mecanismo, os resultados encontrados demonstram um efeito negativo e significativo da concorrência de importações chinesas sobre a renda dos trabalhadores brasileiros no período de 2000 a 2016. Em relação à qualidade das exportações, verifica-se nas estimativas que o efeito é positivo e significativo, evidenciando que a concorrência de importações chinesas aumentou os acidentes e doenças do trabalho, nos diferentes quartis de qualidade. Pode-se verificar que os setores com menor qualidade nos seus produtos, menores quartis, (Q0,25, Q0,50 e Q0,75), sentem mais o efeito da concorrência de importações chinesas sobre os acidentes e doenças do trabalho, em comparação ao quartil maior $(\mathrm{Q} 1,0)$.

Uma das limitações deste trabalho trata-se do problema das subnotificações dos acidentes e doenças do trabalho, ou seja, os trabalhadores que sofreram algum incidente e não notificaram o mesmo diante da empresa ou da Previdência Social. No entanto, espera-se que as subnotificações afetem da mesma forma ambos os setores. Ademais, os efeitos fixos incluídos tanto de setor como de tempo, têm o intuito de mitigar o efeito de características específicas de setor, produtos, estados, dentre outros, que não são observadas. Sendo assim, as subnotificações não invalidariam as análises aqui estimadas, pois as mesmas foram controladas através de efeitos fixos.

Embora questões trabalhistas tenham assumido um papel importante na negociação de políticas, houve relativamente poucos estudos que evidenciaram a ligação entre comércio e mercado de trabalho, de modo específico, a saúde dos trabalhadores. Dada a crescente integração dos mercados, torna-se importante a análise do estudo em questão, com o intuito de contribuir para a formulação de políticas públicas que tenham como foco a melhoria da situação no mercado de trabalho, bem como, uma maior exigência no cumprimento de leis trabalhistas. Portanto, ao compreender os determinantes do aumento dos acidentes e doenças dos trabalhadores, as ações seriam melhores proferidas e focadas nesses condicionantes. Devido à pouca literatura encontrada nessa área e à importância que o bem-estar do trabalhador possui tanto para a sociedade quanto para o desenvolvimento de um país, se faz importante o passo dado no presente estudo e as contribuições de futuras pesquisas.

\section{Agradecimentos}

O presente trabalho foi realizado com apoio da Coordenação de Aperfeiçoamento de Pessoal de Nível Superior - Brasil (CAPES) - Código de Financiamento 001. Agradecimento especial a FAPEMIG - Fundação de Amparo à Pesquisa do Estado de Minas Gerais pela bolsa concedida. 


\section{Referências Bibliográficas}

Adda, J. \& Fawaz, Y. (2020). The health toll of import competition. The Economic Journal, London, v. 130, p. 1501-1540.

Alcalá, F. (2016). Specialization across goods and export quality. Journal of International Economics, Amsterdam, v. 98, p. 216-232.

Almeida, A. T. C. \& Araújo Júnior, I. T. (2017). Diferenciais compensatórios de salário para trabalhadores com preferências heterogêneas: evidências para o caso brasileiro. In: XXII Encontro Regional de Economia. Fortaleza: ANPEC.

Angrist, J. D. \& Pischke, J. S. (2008). Mostly Harmless Econometrics: an Empiricist's Companion. Princeton: Princeton University Press.

Antoniades, A. (2015). Heterogeneous firms, quality, and trade. Journal of International Economics, Amsterdam, v. 95, p. 263-273.

Anwar, S. \& Sun, S. (2018). Foreign direct investment and export quality upgrading in China's manufacturing sector. International Review of Economics E Finance, Amsterdam, v. 54, p. 289-298.

Autor, D., Dorn, D. \& Hanson, G. H. (2013). The China syndrome: local labor market effects of import competition in the United States. American Economic Review, Nashville, v. 103, p. 2121-68.

Bas, M. \& Strauss-Kahn, V. (2015). Input-trade liberalization, export prices and quality upgrading. Journal of International Economics, Amsterdam, v. 95, p. 250-262.

Bastos, P. \& Silva, J. (2010). The quality of a firm's exports: where you export to matters. Journal of International Economics, Amsterdam, v. 82, p. 99-111.

Benguria, F. \& Ederington, J. (2017). Decomposing the effect of trade on the gender wage gap. Rochester: SSRN. Disponivel em: https://ssrn.com/abstract $=2907094$.

Bernard, A. B., Jensen, J. B. \& Schott, P. K. (2006a). Survival of the best fit: exposure to low-wage countries and the (uneven) growth of US manufacturing plants. Journal of International Economics, Amsterdam, v. 68, p. 219-237.

Bernard, A. B., Jensen, J. B. \& Schott, P. K. (2006b). Trade costs, firms and productivity. Journal of Monetary Economics, Amsterdam, v. 53, p. 917-937.

Bloom, N., Draca, M. \& Van Reenen, J. (2016). Trade induced technical change? The impact of Chinese imports on innovation, IT and productivity. The Review of Economic Studies, Oxford, v. 83, p. 87-117.

Brambilla, I. \& Porto, G. G. (2016). High-income export destinations, quality and wages. Journal of International Economics, Amsterdam, v. 98, p. 21-35.

Brown, D. K., Deardorff, A. V. \& Stern, R. M. (1996). International Labor Standards and Trade: a Theoretical Analysis. Ann Arbor: Institute of Public Policy Studies, University of Michigan. 
Bustos, P. (2011). Trade liberalization, exports, and technology upgrading: evidence on the impact of MERCOSUR on Argentinian firms. American Economic Review, Nashville, v. 101, p. 304-40.

Colantone, I., Crino, R. \& Ogliari, L. (2019). Globalization and mental distress. Journal of International Economics, Amsterdam, v. 119, p. 181-207.

Costa, F., Garred, J. \& Pessoa, J. P. (2016). Winners and losers from a commodities-for-manufactures trade boom. Journal of International Economics, Amsterdam, v. 102, p. 50-69.

DATAPREV (2019). Empresa de Tecnologia e Informações da Previdência Social. Brasília: Base de Dados Históricos de Acidentes do Trabalho. Disponível em: http://www3.dataprev.gov.br/aeat/. Acesso em: 12 mar. 2019.

Dix-Carneiro, R. \& Kovak, B. K. (2017). Trade liberalization and regional dynamics. American Economic Review, Nashville, v. 107, p. 2908-46.

Dix-Carneiro, R., Soares, R. R. \& Ulyssea, G. (2018). Economic shocks and crime: evidence from the Brazilian trade liberalization. American Economic Journal: Applied Economics, Nashville, v. 10, p. 158-95.

Esteves, L. A. (2008). Salários e risco de acidentes de trabalho: evidências de diferenciais compensatórios para a indústria manufatureira. Economia Aplicada, Ribeirão Preto, v. 12, p. 275-287.

Flach, L. (2016). Quality upgrading and price heterogeneity: evidence from Brazilian exporters. Journal of International Economics, Amsterdam, v. 102, p. 282-290.

Gaddis, I. \& Pieters, J. (2017). The gendered labor market impacts of trade liberalization evidence from Brazil. Journal of Human Resources, Madison, v. 52, p. 457-490.

Hallak, J. C. (2006). Product quality and the direction of trade. Journal of International Economics, Amsterdam, v. 68, p. 238-265.

Hallak, J. C. \& Schott, P. K. (2011). Estimating cross-country differences in product quality. The Quarterly Journal of Economics, Cambridge, v. 126, p. 417-474.

Harkness, E. F., Macfarlane, G. J., Nahit, E., Silman, A. J. \& McBeth, J. (2004). Mechanical injury and psychosocial factors in the work place predict the onset of widespread body pain: a two-year prospective study among cohorts of newly employed workers. Arthritis E Rheumatism, Atlanta, v. 50, p. 16551664 .

Hummels, D. \& Klenow, P. J. (2005). The variety and quality of a nation's exports. American Economic Review, Nashville, v. 95, p. 704-723.

Hummels, D., Munch, J. \& Xiang, C. (2015). No Pain, No Gain: the Effects of Exports on Job Injury and Sickness. Cambridge: National Bureau of Economic Research. (Working Paper n. 22365).

Kivimäki, M. \& Kawachi, I. (2015). Work stress as a risk factor for cardiovascular disease. Current Cardiology Reports, London, v. 17, p. 1-9. 
Kugler, M. \& Verhoogen, E. (2012). Prices, plant size, and product quality. The Review of Economic Studies, Oxford, v. 79, p. 307-339.

McManus, T. C. \& Schaur, G. (2016). The effects of import competition on worker health. Journal of International Economics, Amsterdam, v. 102, p. 160172.

MDIC - Ministério da Indústria, Comércio Exterior e Serviços (2019). Base de dados do comércio exterior brasileiro. Brasília: MDIC. Disponível em: http://comexstat.mdic.gov.br/pt/home. Acesso em: 11 mar. 2019.

Melitz, M. J. (2003). The impact of trade on intra-industry reallocations and aggregate industry productivity. Econometrica, New Haven, v. 71, p. 16951725 .

O’Reilly, D. \& Rosato, M. (2013). Worked to death? A census-based longitudinal study of the relationship between the numbers of hours spent working and mortality risk. International Journal of Epidemiology, Oxford, v. 42, p. $1820-1830$.

Pavcnik, N. (2002). Trade liberalization, exit, and productivity improvements: Evidence from Chilean plants. The Review of Economic Studies, Oxford, v. 69 , p. $245-276$.

Pierce, J. R. \& Schott, P. K. (2016). The surprisingly swift decline of US manufacturing employment. American Economic Review, Nashville, v. 106, p. 163262.

Pinheiro, A. C., Markwald, R. \& Pereira, L. V. (2002). O desafio das exportações. Rio de Janeiro: Banco Nacional de Desenvolvimento Econômico e Social. Disponível em: https://web.bndes.gov.br/bib/jspui/bitstream/1408/2064/1/LivroAcesso em: 05 jul. 2020.

Verhoogen, E. A. (2008). Trade, quality upgrading, and wage inequality in the Mexican manufacturing sector. The Quarterly Journal of Economics, Cambridge, v. 123, p. 489-530.

Virtanen, M., Heikkilä, K., Jokela, M., Ferrie, J. E., Batty, G. D., Vahtera, J. \& Kivimäki, M. (2012). Long working hours and coronary heart disease: a systematic review and meta-analysis. American Journal of Epidemiology, Oxford, v. 176 , p. 586-596.

WITS - World Integrated Trade Solution (2019). Disponível em: https://wits.worldbank.org/WITS/WITS/Restricted/Login.aspx. Acesso em: 20 mar. 2019. 


\section{Apêndice A}

Tabela A.1: Setores considerados na análise de acordo com o Código CNAE

Agricultura, Pecuária e Serviços Relacionados (0110, 0111, 0120); Silvicultura, Exploração Florestal e Serviços Relacionados (0200); Pesca, Aquicultura e Atividades dos Serviços Relacionados com estas Atividades (0500); Extração de Petróleo e Gás Natural e Serviços Relacionados (1100); Extração de Minerais Metálicos (1300); Extração de Minerais Não-Metálicos (1400); Fabricação de Produtos Alimentícios e Bebidas (1501, 1502, 1503, 1504, 1505); Fabricação de Produtos do Fumo (1600); Fabricação de Produtos Têxteis (1700); Confecção de artigos do vestuário e acessórios (1800); Preparação de Couros e Fabricação de Artefatos de Couro, Artigos de Viagem e Calçados (1901, 1902); Fabricação de Produtos de Madeira (2000); Fabricação de Celulose, Papel e Produtos de Papel (2100); Edição, Impressão e Reprodução de Gravações (2200); Fabricação de Coque, Refino de Petróleo, Elaboração de Combustíveis Nucleares e Produção de Álcool (2301, 2302); Fabricação de Produtos Químicos (2401, 2402, 2403); Fabricação de Artigos de Borracha e Plástico (2501, 2502); Fabricação de Produtos de Minerais Não-Metálicos (2601, 2609); Metalurgia Básica (2700); Fabricação de Produtos de Metal - Exceto Máquinas e Equipamentos (2800); Fabricação de Máquinas e Equipamentos (2900); Fabricação de Máquinas para Escritório e Equipamentos de Informática (3000); Fabricação de Máquinas, Aparelhos e Materiais Elétricos (3100); Fabricação de Material Eletrônico e de Aparelhos e Equipamentos de Comunicações (3200); Fabricação de Equipamentos de Instrumentação Médico-Hospitalares, Instrumentos de Precisão e Ópticos, Equipamentos para Automação Industrial, Cronômetros e Relógios (3300); Fabricação de Outros Equipamentos de Transporte (3501, 3502, 3503, 3509); Fabricação de Móveis e Indústrias Diversas (3601); Atividades de Informática e Conexas (7201); Serviços Prestados Principalmente às Empresas (7409) e Atividades Recreativas, Culturais e Desportivas (9201)

Fonte: Resultado da pesquisa.

Nota: Os CNAE: 7201, 7409 e 9201 são os setores considerados "não comercializáveis".

\section{Apêndice B}

Tabela B.1: Estatísticas Descritivas

\begin{tabular}{l|ccc}
\hline \multicolumn{1}{c|}{ Variável } & Média & $\begin{array}{c}\text { Desvio } \\
\text { Padrão }\end{array}$ & $\begin{array}{c}\mathbf{n}^{\mathbf{o}} \\
\text { observações }\end{array}$ \\
\hline Log(Acidentes e Doenças do Trabalho) & 3,359 & 2,124 & 14,999 \\
Log(Concorrência Chinesa) & 0,0098 & 0,0452 & 14,999 \\
Escolaridade & 8,131 & 2,356 & 14,999 \\
Sexo (Homem) & 0,775 & 0,189 & 14,999 \\
Idade & 35,826 & 5,224 & 14,999 \\
Raça (Branco) & 0,453 & 0,242 & 14,999 \\
Estado Civil (Casado) & 0,479 & 0,228 & 14,999 \\
Ocupação & 0,221 & 0,234 & 14,999 \\
Tamanho do estabelecimento & 4,717 & 1,865 & 14,999 \\
\hline
\end{tabular}

Fonte: Resultado da Pesquisa 


\section{Apêndice C}

Tabela C.1: Estimativa do Efeito da Concorrência Chinesa sobre os Acidentes e Doenças do Trabalho (1ºstágio MQ2E)

\begin{tabular}{c|ccc|ccc}
\hline & \multicolumn{3}{|c|}{ MQO } & \multicolumn{3}{c}{ MQ2E } \\
\cline { 2 - 7 } & $(1)$ & $(2)$ & $(3)$ & $(4)$ & $(5)$ & $(6)$ \\
\hline
\end{tabular}

Variável dependente: $\log$ (Acidentes e Doenças do Trabalho)

\begin{tabular}{|c|c|c|c|c|c|}
\hline América do Sul & - & - & $\begin{array}{l}0,774^{* * *} \\
(0,028)\end{array}$ & $\begin{array}{l}0,775^{* * *} \\
(0,026)\end{array}$ & $\begin{array}{c}0,774^{* * *} \\
(0,026)\end{array}$ \\
\hline Idade & - & - & - & - & $\begin{array}{l}-0,000 \\
(0,000)\end{array}$ \\
\hline Sexo (Masculino) & - & - & - & - & $\begin{array}{c}-0,008^{* *} \\
(0,003)\end{array}$ \\
\hline Raça/Cor (Branco) & - & - & - & - & $\begin{array}{l}-0,0006 \\
(0,0017)\end{array}$ \\
\hline Ocupação & - & - & - & - & $\begin{array}{c}-0,003^{* * *} \\
(0,0009)\end{array}$ \\
\hline Escolaridade & - & - & - & - & $\begin{array}{l}-0,0003 \\
(0,0003)\end{array}$ \\
\hline $\begin{array}{l}\text { Estado Civil } \\
\text { (Casado) }\end{array}$ & - & - & - & - & $\begin{array}{l}-0,002 \\
(0,001)\end{array}$ \\
\hline $\begin{array}{c}\text { Tamanho do } \\
\text { Estabelecimento }\end{array}$ & - & - & - & - & $\begin{array}{c}0,000 \\
(0,000)\end{array}$ \\
\hline Controles & - & - & - & - & Sim \\
\hline Efeitos fixos de estado & - & - & - & Sim & Sim \\
\hline Efeitos fixos de setor & - & - & - & Sim & Sim \\
\hline Efeitos fixos de ano & - & - & - & Sim & Sim \\
\hline Observações & - & - & 14,975 & 14,975 & 14,975 \\
\hline Teste F & - & - & $716,82^{* * *}$ & $841,20^{* * *}$ & $867,85^{* * *}$ \\
\hline
\end{tabular}

Fonte: Resultado da pesquisa.

Notas: Todas as estimativas estão ponderadas pela população de cada estado no ano de 2000 (ano base);

${ }^{* * *} \mathrm{p}<0,01,{ }^{* *} \mathrm{p}<0,05,{ }^{*} \mathrm{p}<0,1$ indicam níveis de significância de $1 \%, 5 \%$ e $10 \%$, respectivamente;

Erros-padrão robustos e clusterizados em nível de macrorregião (Norte, Sul, Sudeste, Nordeste e Centro-Oeste) estão entre parênteses. Em todas as estimativas controla-se por Tendências Específicas de Estados. Variáveis de controle consideradas: idade, sexo, raça, ocupação, escolaridade, estado civil e tamanho do estabelecimento. 
